\title{
ipen
}

AUTARQUIA ASSOCIADA À UNIVERSIDADE DE SÃO PAULO

\section{Caracterização da crotamina e seu efeito sobre a contratilidade da musculatura lisa do ducto deferente de rato}

MARIANA D'ANGELO MARTINS KMAID EL-CORAB

Orientador: Dr. Patrick Jack Spencer

Co-orientador: Dr. Cláudio Fontes Souza

São Paulo 
Dedico este trabalho a toda a minha família e amigos, com quem sempre pude contar em todos os momentos !!!! 


\section{Agradecimentos}

Agradeço primeiramente a Deus pela minha existência e vitalidade.

Ao meu orientador, Dr. Patrick Jack Spencer, pela confiança, pelo apoio constante, sugestões e pelos ensinamentos adquiridos.

Ao meu co-orientador, Dr. Cláudio Fontes Souza, por todo apoio, confiança e sobretudo por ser um exemplo de simplicidade a ser seguido. Sua participação foi fundamental neste trabalho.

A minha amiga Dra. Karina Corleto, por toda ajuda no laboratório, pelos ensinamentos, conselhos e companheirismo. Em especial pelos momentos de descontração que tornavam as tardes de experimento mais divertidas.

Ao Dr. Isaltino Marcelo Conceição, por disponibilizar seu laboratório para os experimentos em órgão isolado e principalmente pelas dicas, sugestões e por se mostrar sempre disposto a ajudar.

A Thalma Ariani e as alunas de iniciação cientifica do laboratório de Farmacologia II do Instituto Butantan, por todo apoio e por terem me acolhido no grupo sempre dispostas a ajudar.

À Dra. Nanci do Nascimento, pelo auxílio no trabalho e pelas sugestões.

Ao Dr. Daniel Carvalho Pimenta pela ajuda na etapa de caracterização da crotamina, alem das sugestões dadas.

Ao Johnny e Jose Maria, pela constante ajuda no laboratório e por ser sempre solícitos e dispostos a ajudar.

Aos colegas Tamara Fucase e Dr. Vincent Louis Viala por sempre se mostrarem dispostos a ajudar, pelas dicas e sugestões.

Aos amigos José Pedro, Paula Juliana Nishimura e Samuel Brito por toda 
ajuda, pelas conversas e desabafos, e por sempre tornarem o ambiente a sua volta muito mais divertido.

Ao amigos e colegas de laboratório Bruno Baessa Chagas, Daniele Gordillo, Marina Gordillo e Marcela Di Giacomo pelo apoio e pelos conselhos.

Aos amigos Bia, Flavio e Natan pelas risadas, pelo apoio e pelos almoços descontraídos no bandejão.

As grandes amigas do IPEN Amanda Mendes, Anna Paula Daniele, Daphne Said e Tania Brambilla por todo suporte emocional em todos os momentos e pelos inúmeros momentos de descontração.

Aos antigos amigos por ainda fazerem parte desta caminhada.

Aos demais pesquisadores e integrantes do Centro de Biotecnologia, por toda a colaboração que, com certeza, foi de grande importância no decorrer deste trabalho.

A todos os funcionários do centro pela organização, manutenção e limpeza do centro.

Aos integrantes da Comissão de Pós-graduação pela ajuda constante nos assuntos burocráticos e pelos momentos divertidos.

Ao IPEN pelo fornecimento da infraestrutura necessária para o desenvolvimento desse trabalho.

A CAPES pelo financiamento do projeto.

E, a vocês, família querida em especial meus pais Charles e Pilar, pelo apoio incondicional e por todos os ensinamentos que jamais serão resumidos a palavras... 
"A tarefa não é tanto ver aquilo que ninguém viu, mas pensar o que ninguém ainda pensou sobre aquilo que todo mundo vê." (Arthur Schopenhauer)

"O conhecimento nos faz responsáveis". (Che Guevara) 


\section{CARACTERIZAÇÃO DA CROTAMINA E SEU EFEITO SOBRE A CONTRATILIDADE DA MUSCULATURA LISA DO DUCTO DEFERENTE DE RATO}

Mariana D’Angelo Martins Kmaid El-Corab

RESUMO

A crotamina, um peptídeo catiônico que possui 42 aminoácidos e 4,88 $\mathrm{kDa}$, é proveniente do veneno de Crotalus durissus terrificus. Ela apresenta características que permitem sua forte interação com alvos moleculares e membranas biológicas e assim foi o primeiro peptídeo de veneno a ser classificado como um CPP (cell penetrating peptide), justificando seus importantes efeitos biológicos e suas diversas atividades farmacológicas. A crotamina é descrita por sua atividade miotóxica, tendo como efeito a paralisia e espasmos das patas traseiras de ratos e camundongos. Esse fenômeno é descrito por ações em canais de $\mathrm{Na}+$ e/ou $\mathrm{K}^{+}$e consequente aumento do influxo intracelular dos níveis do íon $\mathrm{Ca}^{2+}$. Estudos a descrevem como um agente despolarizante utilizando a musculatura esquelética como modelo experimental. Outra atividade descrita da crotamina é um aumento na liberação basal de acetilcolina ( $\mathrm{ACh}$ ) e dopamina no sistema nervoso central de ratos. Até o momento, pouco ou nenhum estudo foi realizado em musculatura lisa. A junção neuromuscular autônoma difere em vários aspectos importantes da já conhecida junção neuromuscular esquelética. $O$ ducto deferente de rato (DDR), um órgão par e tubular pertencente à genitália acessória masculina, foi utilizado como modelo experimental por ser um dos órgãos periféricos mais densamente inervados pelo sistema nervoso autônomo simpático. Esse fato, o torna uma importante ferramenta para estudos que envolvam a neurotransmissão e a ação de drogas adrenérgicas. O objetivo do presente trabalho é investigar o efeito da crotamina na contração da musculatura lisa. A crotamina foi isolada a partir do veneno de $C$. $d$. terrificus por cromatografia de exclusão molecular seguida de troca iônica. Os estudos em modelos animais foram realizados utilizando o DD (porção prostática) de ratos Wistar com 5 meses de idade entre $350 \mathrm{~g}$ (protocolo CEUA 1261/14). O estudo de neurotransmissão foi feito em 
sistema de órgão isolado $(n=6)$ por estimulação elétrica transmural com tensão de 70V, 3ms de duração em frequências de 0,05 (30 min) e 1; 510 e $20 \mathrm{~Hz}$ (30 seg). A contração isométrica foi registrada em gramas de tensão. Em todos os experimentos a crotamina $(0,1 ; 0,5$ e $1 \mathrm{~g} / \mathrm{ml})$ incubada $30 \mathrm{~min}$ antes da estimulação. $O$ efeito máximo de contração $\left(E_{\max }\right)$ do componente fásico e tônico foi usado como medida. O componente pós-sináptico foi avaliado por meio de curvas dose-resposta de noradrenalina e dose única de ATP $\left(10^{-3} \mathrm{M}\right)$ na presença ou ausência da crotamina. A diferença estatística foi avaliada pelo teste-t de student $(P \leq 0,05)$. Os ensaios de estimulação elétrica de baixa frequência $(0,05 \mathrm{~Hz})$ revelaram que a crotamina $(0,1$ e $0,5 \mu \mathrm{g} / \mathrm{ml})$ promoveu uma diminuição da contração do $\operatorname{DDR}(95,7 \pm 4,6 \%$ e $85,4 \pm 5,9 \%$, respectivamente) enquanto que na dose de $1 \mu \mathrm{g} / \mathrm{mL}$ de crotamina este efeito não foi significativo.

$\mathrm{Na}$ curva de freqüência observamos também com as mesmas concentrações de crotamina uma tendência à diminuição da contração fásica e tônica enquanto que a dose de $1 \mu \mathrm{g} / \mathrm{mL}$ promoveu um aumento na contração fásica na freqüência de $20,0 \mathrm{~Hz}((3,2 \pm 0,3)$ em relação ao controle $(2,2 \pm 0,2)$. $O$ componente pós-sináptico não foi alterado pela crotamina conforme evidenciado pela curva concentração-resposta de noradrenalina e concentração única de ATP. Com base nos resultados obtidos, concluímos que a crotamina atua apenas no componente pré-sináptico da contração do DDR, provavelmente interferindo na neuroliberação de ATP e noradrenalina. Ela apresenta um efeito bifásico, dependendo da dose utilizada, inibindo ou potencializando a resposta, efeito semelhante ao da $\beta$-defensinas, uma proteína cuja estrutura se assemelha bastante com a da crotamina. 


\title{
CHARACTERIZATION OF CROTAMINE AND ITS EFFECT IN THE SMOOTH MUSCLE CONTRACTION OF RAT VAS DEFERENS
}

\author{
Mariana D'Angelo Martins Kmaid El-Corab
}

\begin{abstract}
Crotamin, a $4.88 \mathrm{kDa}$ polypeptide composed of 42 amino acids, is derived from the venom of Crotalus durissus terrificus. It presents features that allow its strong interaction with molecular targets and biological membranes and was the first venom peptide to be classified as a CPP (cell penetrating peptide), justifying the important biological effects and different pharmacological activities of crotamine. It is described by its myotoxic activity, having the effect of paralysis and spasms of the hind legs of mice and rats. This phenomenon is described by actions on $\mathrm{Na}^{+}$channels and / or $\mathrm{K}^{+}$and the resulting increase in intracellular influx of $\mathrm{Ca}^{2+}$ ion levels. Studies describe crotamine as a depolarizing agent and neurotransmitter release inductor using the skeletal muscle as an experimental model. Another activity of crotamine described is an increase in the basal release of acetylcholine (ACh) and dopamine in the central nervous system of rats. To date, few or no study has been performed in smooth muscle. The autonomous neuromuscular junction differs in several important aspects of already known skeletal neuromuscular junction. The vas deferens, a pair and tubular organ belonging to the male accessory genitalia, was used as experimental model because it is one of the most densely peripheral organs innervated by the sympathetic nervous system. This fact makes it an important tool for studies involving the neurotransmission and the action of adrenergic drugs. A better understanding of crotamine mechanism of action is fundamental to the development of a pharmacological agent or a possible drug. In this context, we aim to investigate the crotamine behaviour in the contraction of the smooth muscle vas deferens through neurogenic stimulation and exogenous drugs.
\end{abstract}


1. INTRODUÇÃO

1.1 Distribuição do gênero Crotalus no Brasil..................................... 1

1.2 Componentes do veneno da Crotalus durissus terrificus ............ 3

1.3 A crotamina

1.3.1 Atividade biológica da crotamina............................................... $\quad 7$

1.4 Neurotransmissão autonômica $\quad 9$

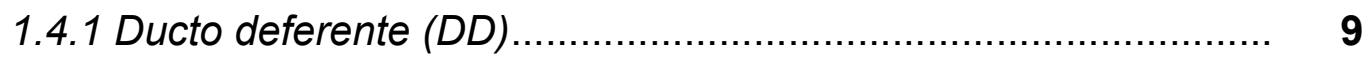

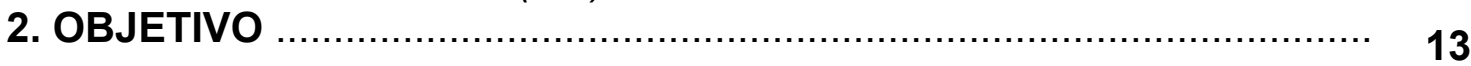

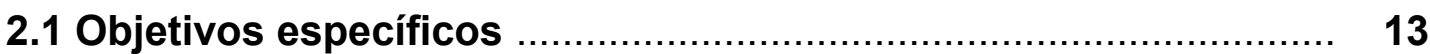

3. MATERIAL E MÉTODOS …...................................................... 14

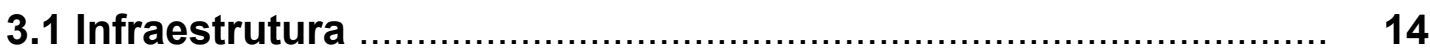

3.2 Isolamento da crotamina ......................................................... 14

3.2.1 Cromatografia de exclusão molecular ................................... 14

3.2.2 Cromatografia de troca iônica ............................................ 14

3.2.3 Cromatografia de exclusão molecular de alta eficiência (HPSEC)

3.2.4 Cromatografia de fase reversa (RP-

HPLC)

3.3 Determinação de massa molecular .......................................... $\quad 15$

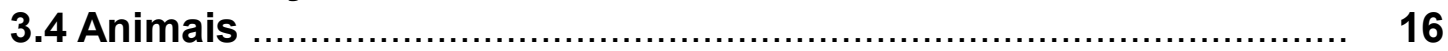

3.5 Experimentos de contração muscular "in vitro" ............................ 16

3.5.1 Isolamento dos ductos deferentes ....................................... 16

3.5.2 Protocolos experimentais ...................................................... 16

3.5.2.1 Estudo da capacidade de liberação de neurotransmissores. $\quad 17$

3.5.2.2 Reação da reatividade pós-sináptica...................................... $\quad 18$

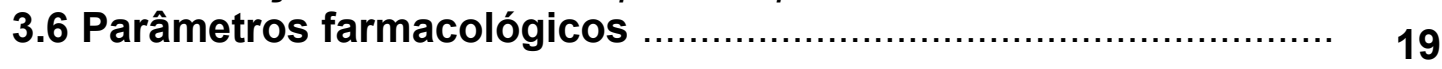

3.6.1 Efeito máximo (Emax) ....................................................... 19

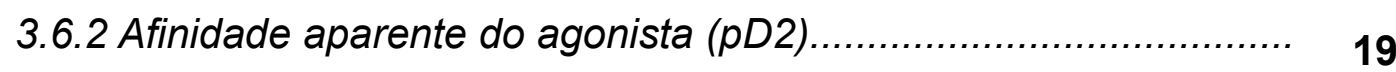

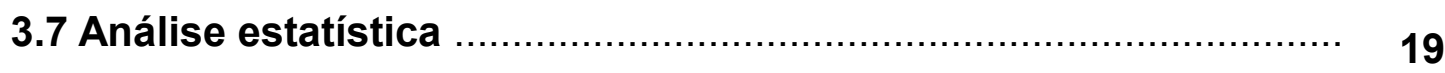

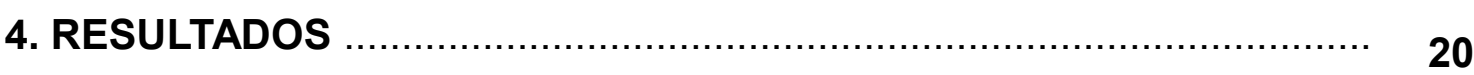

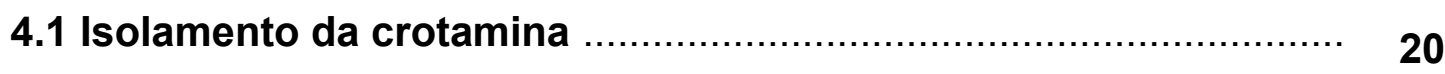

4.2 Análise da crotamina por Cromatografia de Fase Reversa ........... 23

4.3 Determinação de massa molecular .............................................. 25

4.4 Curva dose resposta de crotamina em baixa frequência .............. 27

4.4.1 Análise de neurotransmissão ................................................... 27 
4.4.1.1 Curva dose resposta de crotamina em contrações induzidas por EE (estimulação elétrica) de baixa frequência $(0,05 \mathrm{~Hz}) \ldots \ldots \ldots \ldots \ldots . . . . . . . .27$

4.4.1.2 Curva de freqüência ....................................................... 29

1- Componente fásico de contração ...................................... 30

2- Componente tônico de contração............................................ 30

4.4.1.3 Contrações isométricas induzidas por concentração única de tiramina

4.5 Estudo do componente pós sináptico de contração

4.5.1 Curva dose-resposta (CDR) - Noradrenalina 32

4.5.2 Dose única de ATP 35

5. DISCUSSÃO 36

6. CONCLUSÃO 43 


\section{LISTA DE FIGURAS}

Figura 1 Porcentagem de acidentes ofídicos por gênero de acordo com o Ministério da Saúde (2008).

Figura 2 Distribuição da espécie Crotalus durissus no território brasileiro.

Figura 3 Conformação estrutural da crotamina.

Figura 4 Sequência primária da crotamina com indicação das pontes dissulfeto

Figura 5 Distribuição da superfície de cargas na estrutura da crotamina em duas orientações distintas

Figura 6 Esquema ilustrando o processo de co-transmissão entre noradrenalina e ATP promovendo a contração fásica e tônica das células musculares do DD

Figura 7 Registro típico da contração do ducto deferente de rato

Figura 8 Cromatograma do veneno total da C.d.terrificus em coluna de exclusão molecular

Figura 9 Perfil cromatográfico da gel filtração analítica da fração correspondente à crotamina oriunda da primeira etapa de fracionamento

Figura 10 Recromatografia da crotamina em coluna de troca catiônica (Mono S).

Figura 11 Gel filtração analítica da fração correspondente à crotamina após a segunda etapa de isolamento

Figura 12 Cromatograma do veneno total da C.d.terrificus em coluna de Fase Reversa

Figura 13 Cromatograma da crotamina proveniente do CEVAP em coluna de Fase Reversa

Figura 14 Sobreposição entre os cromatogramas do Veneno total de C.d.terrificus e a crotamina.

Figura 15 Espectro da crotamina analisada por infusão direta.

Figura 16 Zoom do pico majoritário para determinação do estado de carga.

Figura 17 Espectro indicando a presença de uma possível isoforma de crotamina.

Figura 18 Zoom do pico minoritário para determinação do estado de 
carga.

Figura 19 Registros (Powerlab/4SP) de contração do DDR após 30 minutos de estabilização na presença de crotamina $(0,1 \mu \mathrm{g} / \mathrm{mL})(A)$, e controle (B) em que o DDR foi submetido à baixa frequência $(0,05 \mathrm{~Hz})$.

Figura 20 Os pontos representam média \pm SEM da porcentagem de contração do DDR

Figura 21 Registro (Powerlab/4SP) da curva de frequência $(1 \mathrm{~Hz}, 5 \mathrm{~Hz}$, $10 \mathrm{~Hz}$ e $20 \mathrm{~Hz}$ ) em que o DDR foi submetido, na ausência (A) e incubado com crotamina (B).

Figura 22 Curva de frequência $(1 \mathrm{~Hz}, 5 \mathrm{~Hz}, 10 \mathrm{~Hz}$ e $20 \mathrm{~Hz})$ do componente fásico em que o DDR foi submetido na presença de diferentes doses de crotamina $(0,1 \mu \mathrm{g} / \mathrm{ml}, 0,5$ $\mu \mathrm{g} / \mathrm{ml}$ e $1 \mu \mathrm{g} / \mathrm{ml})$.

Figura 23 Curva de frequência $(1 \mathrm{~Hz}, 5 \mathrm{~Hz}, 10 \mathrm{~Hz}$ e $20 \mathrm{~Hz})$ do componente tônico de contração em que o DDR foi submetido na presença de diferentes doses de crotamina $(0,1 \mu \mathrm{g} / \mathrm{mL}, 0,5 \mu \mathrm{g} / \mathrm{mL}$ e $1 \mu \mathrm{g} / \mathrm{mL})$.

Figura 24 O histograma representa a contração do DDR, proporcionada por concentração única de tiramina $\left(10^{-4} \mathrm{M}\right)$ na ausência (controle) e na presença e de crotamina (1 $\mu \mathrm{g} / \mathrm{mL})$ ou TEA $(1000 \mu \mathrm{M})$.

Figura 25 Curva concentração resposta de noradrenalina na ausência (controle) e na presença de crotamina em diferentes doses

Figura 26 Curva concentração resposta de noradrenalina na ausência (controle) e na presença de TEA em diferentes doses (100Mm, 300Mm e $1000 \mathrm{mM})$.

Figura 27 Histograma representa a porcentagem de contração do DDR induzida pela dose de $10^{-3} \mathrm{M}$ de ATP em relação ao efeito máximo proporcionado por dose única de $\mathrm{KCl} 80 \_\mathrm{mM}$ 


\section{LISTA DE TABELAS}

Tabela 1

Letalidade dos acidentes ofídicos por gênero de

serpentes

Tabela 2 Valores expressos em média \pm erro padrão do $\mathrm{pD}_{2}$ e efeito máximo $\left(E_{\max }\right)$ extraídos da curva concentração resposta de noradrenalina na ausência e na presença de crotamina.

Tabela 3 Valores expressos em média \pm erro padrão do $\mathrm{pD}_{2}$ e Efeito máximo extraídos da curva concentração resposta de 34 noradrenalina na ausência e na presença de TEA. 


\section{LISTA DE ABREVIATURAS E SIGLAS}

ACh - Acetilcolina

ADP - Adenosina difosfato

AMPs - Peptideos antimicrobianos

ANOVA - Analise de variância

ATP - Adenosina trifosfato

$\mathrm{Ca}^{2+}$ - Cálcio

$\mathrm{CaCl}_{2}-$ Cloreto de Cálcio

CEVAP - Centro de Estudos de Venenos e Animais Peçonhentos 
$\mathrm{CO}_{2}-$ Dióxido de carbono

COMT - Acetol-O-metiltransferase

$C P P$ - Cell penetreting peptide

DD - Ducto deferente

DDR - Ducto deferente de rato

$E_{\max }-$ Efeito máximo

HPSEC - Cromatografia de exclusão molecular de alta eficiência

$\mathrm{IP}_{3}$ - Trifosfato de inositol

$\mathrm{K}^{+}$- Potássio

$\mathrm{KCl}$ - Cloreto de potássio

MAO - Monoamino oxidase

$\mathrm{MgCl}_{2}$ - Cloreto de magnésio

MLC Kinase - Miosinaquinase

$\mathrm{Na}^{+}$- Sódio

$\mathrm{NA}$ - noradrenalina

$\mathrm{NaCl}$ - Cloreto de sódio

$\mathrm{NaHCO}_{3}-$ Carbonato de sódio

$\mathrm{NaH}_{2} \mathrm{PO}_{4}$ - Fosfato de sódio

pD2 - Afinidade aparente do agonista

$\mathrm{pl}$ - Ponto isoelétrico

PKC - Proteína kinase $C$

PLC - Fosfolipase C

TEA - Tetraetilamonio

\section{LISTA DE DROGAS E REAGENTES}

Acetonitrila: $\mathrm{CH}_{3} \mathrm{CN}$

Acido fórmico 0,05\%: $\mathrm{CH}_{2} \mathrm{O}_{2}$

Adenosina trifosfato: ATP $10^{-4}$

Cloreto de potássio: $\mathrm{KCl}$

Cloreto de sódio: $\mathrm{NaCl}$

Dióxido de carbono: $\mathrm{CO}_{2}$

Noradrenalina: -(+)-arterenol chloride $\left(\mathrm{C}_{8} \mathrm{H}_{11} \mathrm{NO}_{3} \mathrm{HCl}\right)$

Tampão formiato de amônio $200 \mathrm{mM}$ pH 3: $\mathrm{NH}_{4} \mathrm{HCO}_{2}$ 
Tampão fosfato de sódio $50 \mathrm{mM} \mathrm{pH} \mathrm{7,8:} \mathrm{NaH}_{2} \mathrm{PO}_{4}$

Tetraetilamonio (TEA): $\mathrm{C}_{8} \mathrm{H}_{20} \mathrm{~N} \cdot \mathrm{Cl}$

Tiramina: $\mathrm{C}_{8} \mathrm{H}_{11} \mathrm{NO}$

Cloreto de sódio: $\mathrm{NaCl}$

Cloreto de Potássio: $\mathrm{KCl}$

Cloreto de Magnésio: $\mathrm{MgCl}_{2}$

Cloreto de Cálcio: $\mathrm{CaCl}_{2}$

Fosfato de sódio: $\mathrm{NaH}_{2} \mathrm{PO}_{4}$

Carbonato de sódio: $\mathrm{NaHCO}_{3}$

Glicose 


\section{INTRODUÇÃO}

São conhecidas cerca de 3.400 espécies de serpentes distribuídas pelo mundo inteiro, classificadas em 27 famílias (Reptile Database, www.reptiledatabase.org, acessado em 20 de outubro de 2015), sendo que apenas 4 produzem secreções tóxicas: Atractaspidae, Colubridae, Elapidae e Viperidae (Mènez, 1994).

As serpentes da família Viperidae possuem o mecanismo de injeção de veneno mais desenvolvido e são divididas em 2 outras subfamílias: Viperinae, encontrada na Eurásia e África, e Crotalinae, que inclui as cascavéis (gênero Crotalus). A subamília Crotalinae é encontrada nas Américas e no sudeste Asiático.

\subsection{Distribuição do gênero Crotalus no Brasil}

Segundo dados de 2008 do Ministério da Saúde (Figura 1), aproximadamente $75 \%$ dos acidentes ocorrem com serpentes pertencentes ao gênero Bothrops. Os gêneros Crotalus, Lachesis e Micrurus representam cerca de $7,5 \%, 3,0 \%$ e $1,0 \%$ dos casos, respectivamente. Estes dados referem-se à acidentes nos quais o gênero da serpente é informada; em 15\% dos casos, aproximadamente, tal informação não é obtida.

Figura 1: Porcentagem de acidentes ofídicos por gênero (Ministério da Saúde, 2008).

Apesar do número de acidentes em humanos causados pelo gênero Crotalus ser relativamente baixo, a letalidade destes acidentes é a mais expressiva, como observada na Tabela 1 (Ministério da Saúde, 2008).

Tabela 1 - Letalidade dos acidentes ofídicos por gênero de serpentes Brasil, 19901993. 


\begin{tabular}{cccc}
\hline Gênero & $\mathrm{n}^{\circ}$ casos & $\mathrm{n}^{\circ}$ óbitos & Letalidade \\
\hline Bothrops & 59.619 & 185 & 0,31 \\
Crotalus & 5.072 & 95 & 1,87 \\
Lachesis & 939 & 3 & 0,95 \\
Micrurus & 281 & 1 & 0,36 \\
Não informado & 13.339 & 69 & 0,52 \\
\hline TOTAL & 79.250 & 359 & 0,45
\end{tabular}

Adaptado de Ministério da Saúde, 2008.

O gênero Crotalus é representado no Brasil por apenas uma espécie, Crotalus durissus e distribuído em cinco subespécies: Crotalus durissus terrificus, encontrada nas zonas altas e secas da região sul oriental e meridional; Crotalus durissus collilineatus, distrubuídas nas regiões secas do centro-oeste, Minas Gerais e norte de São Paulo; Crotalus durissus cascavella, encontrada nas áreas da caatinga do nordeste; Crotalus durissus ruruima, observada na região norte do país; Crotalus durissus marajoensis, observada na ilha de Marajó (Kasturiratne et al., 2008).

Na Figura 2 é possível observar a distribuição da espécie $C$. durissus no Brasil.

Figura 2: Distribuição da espécie $C$. durissus no território brasileiro (Kasturiratne et al., 2008).

Considerando especificamente a subespécie $C$. $d$. terrificus, cujo veneno é objeto deste estudo, dados revelam que cerca de $7,5 \%$ dos acidentes ofídicos no Brasil são decorrentes da espécie, apresentando ainda alta taxa de mortalidade (Cardoso et al., 2003; Ferreira Júnior et al., 2006).

\subsection{Componentes do veneno da C. d. terrificus}

Os venenos ofídicos em geral são misturas complexas constituídas por proteínas (70 a $90 \%$ do peso seco), em sua maioria toxinas ou enzimas tóxicas. A 
fração não proteica dos venenos das serpentes consiste de cátions e ânions inorgânicos, substâncias de baixa massa molecular como aminoácidos, peptídeos, lipídeos, nucleotídeos e nucleosídeos, carboidratos e aminas (Devi, 1971; Stocker, 1990). Estes venenos são descritos por serem uma fonte importante de substâncias bioativas de grande interesse toxinológico e farmacológico.

Os venenos extraídos de cascavéis brasileiras (venenos crotálicos) são caracterizados por possuírem efeitos neurotóxico, nefrotóxico, miotóxico, antitrombolítico, antiplaquetário e analgésico (Toyama et al., 2005; Mancin, et al., 1998; Evangelista, et al. 2008). Outro importante efeito dos venenos crotálicos foi observado por Graham et al. (2005), que descrevem uma atividade hipotensora do sistema vascular.

No caso específico do veneno da subespécie C. d. terrificus, há 5 componentes farmacologicamente ativos identificados até então: convulxina, delta toxina, giroxina, crotoxina e crotamina.

Isolada em 1970, a convulxina é uma glicoproteína neurotóxica de alta massa molecular, cerca de 72 kDa. Ela provoca distúrbios no sistema nervoso autônomo caracterizados por convulsões tônico-clônicas, alterações circulatórias e respiratórias, ativação e agregação plaquetária na ausência de fibrinogênio (Vargaftig et al., 1983).

A delta toxina, isolada por Campos em 2006, apresenta massa molecular de 40 kDa e ativa agregação plaquetária em concentrações muito baixas. Ela foi assim denominada por Vital Brazil, em 1980, ao sugerir a existência de uma toxina que teria seu pico de eluição entre a convulxina e a giroxina, quando realizado o fracionamento por cromatografia de exclusão molecular do veneno e que estaria envolvida na agregação plaquetária, alteração da permeabilidade vascular, além de causar grande hemoconcentração.

Em 1961 a giroxina, uma serino protease de 34 kDa com efeitos neurotóxicos, foi parcialmente caracterizada e descrita como uma neurotoxina nãoletal, responsável pela indução de uma síndrome neurológica em ratos. Este efeito apresenta movimentos circulatórios do corpo ao longo de seu eixo longitudinal, similares ao rolamento de um barril. A giroxina apresenta ainda atividade coagulante do fibrinogênio no plasma de mamíferos, exercendo assim uma atividade trombolítica (Alexander et al., 1988).

A crotoxina representa cerca de $70 \%$ da massa total do veneno da $C$. $d$. terrificus. Foi a primeira neurotoxina animal a ser purificada e cristalizada (Slotta \& 3 
Fraenkel-Conrat, 1938). A crotoxina exerce sua função fisiopatológica por inibir a transmissão neuromuscular, bloqueando a liberação de acetilcolina (Hortnagel \& Hanin, 1992). Em adição aos seus efeitos pré-sinápticos, a crotoxina também age de forma pós-sináptica bloqueando a resposta da acetilcolina deixando o receptor colinérgico em um estado conformacional inativo (Vital Brazil \& Excell, 1971; Vital Brazil et al., 1966).

Um dos componentes do veneno crotálico que despertou grande interesse por suas propriedades na musculatura esquelética foi a crotamina, que tem mostrado um amplo espectro de atividades biológicas com potenciais aplicações farmacológicas (Yamane et al., 2013).

\subsection{Crotamina}

A crotamina foi primeiramente isolada, por meio de métodos eletroforéticos, por Gonçalves \& Vieira (1950). Possui massa molecular de 4,8 kDa e é composta por 42 aminoácidos (Laure, 1975), apresentando, dentre outros resíduos, 7 resíduos de aminoácidos aromáticos: 1 tirosina, 2 histidinas, 2 triptofanos e 2 fenilalaninas, apresentando alto grau de homologia com miotoxinas. É uma toxina extremamente básica, com pl = 10.3 (Gonçalves, 1956) devido à presença de 11 aminoácidos básicos (9 lisinas e 2 argininas). Estes aminoácidos promovem uma superfície carregada positivamente para estes peptídeos (Rádis-Baptista \& Kerkis et al., 2011).

Em 2013, Coronado et al. isolaram e determinaram a estrutura cristalográfica da crotamina (Figura 3). A formação topológica foi classificada como $\alpha_{1} \beta_{1} \alpha_{2} \beta_{2}$. A estrutura $\alpha_{1}$ é formada pelos resíduos de lisina $(2-7)$. Na sequência, observa-se a formação de duas estruturas do tipo folha $\beta$ antiparalela, formada pelos resíduos glicina-9 a prolina-13 $\left(\beta_{1}\right)$ e triptofano-34 a lisina-38 $\left(\beta_{2}\right)$, localizadas na região interna da molécula. Uma pequena $\alpha$-hélice é formada pelos resíduos prolina-20 a serina-23. A toxina, como já mencionado anteriormente, é estabilizada por 3 pontes dissulfeto (destacadas em amarelo na Figura 3): cisteína-4 e cisteína-36, cisteína11 e cisteína-30, cisteína-18 e cisteína-37.

A ponte formada pelos resíduos cisteína-4 a cisteína-36 fixa o segmento entre a estrutura $\alpha_{1}$ e $\beta_{2}$. Já as formações $\beta_{1}$ e $\alpha_{2}$ são conectadas por um loop flexível entre os resíduos de lisina-14 a leucina-19. Outro loop mais extenso e flexível, formado entre os resíduos ácido aspártico-24 a arginina-33, conecta as estruturas $\alpha_{2}$ e $\beta_{2}$. As formações do tipo folha $\beta$ são estabilizadas por pontes de hidrogênio que 
conectam as estruturas $\beta_{1}$ e $\beta_{2}$, envolvendo os resíduos histidina-10 a cisteína-37 e fenilalanina-12 a lisina-35. As pontes de hidrogênio entre as estruturas $\beta_{2}$ e $\alpha_{2}$ são formadas pelos resíduos serina-23 a lisina-38. Duas pontes de hidrogênio conectam ainda a estrutura $\beta_{2}$ a região C-terminal em $\beta$-turn (Coronado et al., 2013).

Figura 3: Conformação estrutural da crotamina. Em amarelo estão representadas as pontes dissulfeto (Coronado et al., 2013).

As 6 cisteínas ligadas por pontes dissulfeto conferem à crotamina alta estabilidade conformacional (Hampe, 1978). A sequência da estrutura primária da crotamina com a indicação das 3 pontes de dissulfeto formadas estão indicadas na Figura 4.

$\begin{array}{lllllllllll}1 & & & & & & \\ \text { Tyr Lys } & \text { Gln } & \text { Cys } & \text { His } & \text { Lys } & \text { Lys } & \text { Gly } & \text { Gly } & \text { His } \\ 11 & & & & & & & & & \\ \text { Cys } & \text { Phe } & \text { Pro } & \text { Lys } & \text { Glu } & \text { Lys } & \text { Ile } & \text { Cys } & \text { Leu } & \text { Pro } \\ 21 & & & & & & & & & \\ \text { Pro } & \text { Ser } & \text { Ser } & \text { Asp } & \text { Phe } & \text { Gly } & \text { Lys } & \text { Met } & \text { Asp } & \text { Cys } \\ 31 & & & & & & & & & \\ \text { Arg Trp } & \text { Arg } & \text { Trp } & \text { Lys } & \text { Cys } & \text { Cys } & \text { Lys } & \text { Lys } & \text { Gly } \\ 41 & & & & & & & & & \\ \text { Ser Gly } & & & & & & & & \end{array}$

Figura 4 - Sequência primária da crotamina com indicação das pontes dissulfeto (Beltran et al., 1990).

Em 2013, Coronado et al. isolaram e determinaram a estrutura cristalográfica da crotamina. O modelo estrutural revelado indicou uma distribuição assimétrica de cargas na superfície da proteína (Figura 5). Assim, regiões catiônicas e regiões hidrofóbicas estão localizadas em lados opostos da molécula, o que, por sua vez, explica um possível modo de interação com fosfolípides carregados negativamente e outros alvos moleculares, justificando as diversas atividades farmacológicas da crotamina. A crotamina é uma molécula relativamente pequena, toda carregada e 5 
seus resíduos hidrofóbicos estão expostos ao solvente.

Figura 5: Distribuição da superfície de cargas na estrutura da crotamina em duas orientações distintas. Superfície azul indica a presença de resíduos básicos (arginina e lisina) e a superfície vermelha indica a presença de resíduos ácidos (ácido aspártico e ácido glutâmico) (Coronado et al., 2013).

\subsubsection{Atividade biológica da crotamina}

Um dos efeitos característicos da crotamina em modelos animais são espasmos e a paralisia das patas traseiras de camundongos, ratos, coelhos e cachorros (Vital Brazil et al. 1979; ) além de dificuldade respiratória.

A crotamina, como um componente tóxico do veneno da cascavel, despolariza e contrai o músculo esquelético, tal efeito foi creditado à ação da crotamina especificamente no aumento do influxo de sódio na musculatura esquelética em experimentos de eletrofisiologia (Hong \& Chang, 1983).

Ao investigar a ação despolarizante da crotamina na musculatura do diafragma de ratos e camundongos, foi observado que a despolarização da membrana poderia revertida por bloqueadores de canais de $\mathrm{Na}^{+}$(Vital Brazil et al., 1979). Contudo, estudos posteriores de eletrofisiologia, demonstraram que esta toxina afeta os canais iônicos de maneira indireta (Rizzi et al., 2007).

Yount et al. (2009) propuseram que a crotamina poderia agir bloqueando canais de $\mathrm{K}^{+}$voltagem-dependente, baseado na proximidade da estrutura tridimensional entre a crotamina e a $\beta$-defensinas humana, cuja ação bloqueadora de canais de $\mathrm{K}^{+}$já estava descrita. Contudo, estudos demonstraram que a $\beta$ defensina em baixa concentração pode promover um efeito contrário, causando vasodilatação e hipotensão arterial devido à ativação e abertura de canais de $\mathrm{K}^{+}$ sensíveis ao $\mathrm{Ca}^{2+}$ e consequente hiperpolarização da célula muscular lisa, verificado em experimentos realizados com macacos e ratos (Liu et al., 2013).

Um dado demonstrado por Peigneur, em 2012, que reforça esse efeito, é o fato da crotamina bloquear de forma reversível canais de $\mathrm{K}^{+}$, observado em oócitos de Xenopus laevis transfectados com RNAm para subtipos de canais. O estudo foi realizado em 16 canais iônicos (12 clones de canais de potássio e 4 clones de canais de sódio) expressos da espécie enquanto a crotamina, na concentração de 3 $\mu \mathrm{M}$, foi eficiente em inibir 3 dos 12 canais de $\mathrm{K}^{+}\left(\mathrm{K}_{\mathrm{v}} 1.1 ., 1.2\right.$ e 1.3), sendo o mais 
sensível o $\mathrm{K}_{\mathrm{v}} 1.3$, ela não apresentou atividade em canais de $\mathrm{Na}^{+}$, confirmando tanto as sugestões de Yount (2009), como os relatos de Rizzi (2007) sobre a inabilidade de interação direta da crotamina em canais de sódio.

Outra atividade descrita da crotamina é um aumento da liberação basal de acetilcolina (ACh) e dopamina no sistema nervoso central de ratos (Camillo et al., 2001).

Estudos comparativos entre a crotamina e a neostigmina, fármaco usado há mais de 75 anos para tratar miastenia gravis, doença autoimune onde há a destruição dos receptores nicotínicos de ACh e como consequência a diminuição da capacidade contrátil, demonstraram resultados positivos em relação à capacidade da crotamina em aumentar a contração muscular esquelética (Hernandez-Oliveira e Silva et al., 2013).

De forma similar aos peptídeos antimicrobianos (AMPs), a crotamina é altamente solúvel em água e é capaz de interagir fortemente com membranas biológicas. Assim, alguns trabalhos têm demonstrado a ação da crotamina em penetrar células, sendo o primeiro peptídeo de veneno a ser classificado como um CPP (cell penetrating peptide) (Rodrigues et al., 2012). Em contraste com outros CPPs e AMPs naturais, a crotamina tem demonstrado um amplo espectro de atividades biológicas com potenciais aplicações biotecnológicas e terapêuticas (Yamane et al., 2013).

Recentemente estudos elucidaram a atividade seletiva da crotamina por células tumorais. A ação antitumoral da crotamina parece envolver alterações nos níveis intracelulares de cálcio, tanto pelo aumento do seu influxo quanto pela liberação de seus estoques intracelulares de organelas como o retículo endoplasmático, mitocôndria e lisossomo (Kerkis et al., 2011). Apesar do seu efeito tóxico em tecidos animais, é descrito como um modelo promissor para aplicações biomédicas e desenvolvimento de medicamentos.

$\mathrm{Na}$ literatura existem relatos consideráveis dos efeitos da crotamina em relação à musculatura estriada esquelética e sua ação sobre a neurotransmissão periférica. Contudo, pouco ou nenhum estudo foi realizado na musculatura lisa até o momento. A junção neuromuscular autônoma difere em vários aspectos importantes da já conhecida junção neuromuscular esquelética. Uma das características essenciais deste modelo é que o neurotransmissor é lançado pelas varicosidades das porções terminais das fibras nervosas da musculatura lisa. 


\subsection{Neurotransmissão autonômica}

A partir dos terminais nervosos, o sinal é transmitido à estrutura seguinte que pode ser outro neurônio ou outro tipo celular qualquer. O ponto de comunicação entre esses terminais nervosos e células efetoras é conhecido como sinapse. Quando um potencial de ação alcança o terminal do neurônio, é desencadeado o processo de exocitose, que culmina na liberação do transmissor químico, conhecido como neurotransmissor, o qual é sintetizado no próprio neurônio. Uma vez liberado, o neurotransmissor é difundido pela fenda sináptica alcançç ando e estimulando receptores de membrana em células pós-sinápticas ou auto-receptores situados no próprio terminal nervoso. Esse processo que ocorre na região sináptica é de extrema importância e caracteriza o processo de neurotransmissão (Burnstock,1988).

Algumas substâncias armazenadas e liberadas pelos neurônios não agem diretamente nas células efetoras, mas alteram a liberação e/ou a ação de outros transmissores, essas substâncias são chamadas de neuromoduladores. Muitas substâncias são neuromoduladoras pela sua capacidade de modificar o processo de neurotransmissão tanto pela modulação pré-sináptica da liberação do transmissor como pela modulação pós-sináptica da ação do transmissor (Burnstock,1988).

O lançamento de um neurotransmissor causa uma mudança no potencial de membrana da célula podendo este ser excitatório ou inibitório. A ligação do neurotransmissor em seu receptor específico da célula efetora resultará em uma resposta. Estudos de neurotransmissão autônoma revelaram uma multiplicidade de neurotransmissores atuantes no Sistema Nervoso Autônomo (Burnstock,1988).

\subsubsection{Ducto deferente}

O ducto deferente (DD), órgão pertencente à genitália masculina, localizado entre a cauda do epidídimo (porção epididimal) e a glândula prostática (porção prostática), tem como principal função de maturação e transporte de espermatozóides provenientes dos ductos seminíferos. Esse transporte é realizado através de contrações musculares mediadas principalmente por mecanismos adrenérgicos (Burnstock, 1988). O DD é um órgão par, tubular, constituído de duas camadas interpoladas de músculo liso, sendo uma delas externa e a outra circular. O DD é inervado por fibras simpáticas provenientes do plexo hipogástrico, cujas 
fibras pré-ganglionares são originadas dos segmentos lombares superiores L2 e L3 (Anton et al, 1977). Ele apresenta algumas características importantes na sua inervação como, por exemplo, a grande densidade de nervos simpáticos que incide sobre este órgão fazendo com que ele seja um dos órgãos periféricos mais densamente inervados pelo sistema nervoso autônomo simpático (Batra, 1974). Esse fato, o torna uma importante ferramenta para estudos que envolvam a fisiologia e a neurotransmissão adrenérgica.

O DD é um órgão, cuja transmissão simpática se caracteriza pelo processo de co-transmissão. Evidencias morfológicas, fisiológicas e farmacológicas demonstram que o ATP, uma purina, age como um co-transmissor com a noradrenalina (Koslov, 2013). A noradrenalina e o ATP são liberados na fenda sináptica e atuam de modo sinérgico (Burnstock,1988). Este processo é denominado co-transmissão simpática, envolvendo ATP e noradrenalina, onde ambos são liberados para a fenda sináptica em diferentes proporções, dependendo do tecido e dos parâmetros de estimulação.

Segundo Koslov em 2013, a estimulação elétrica de nervos simpáticos do DD de ratos, camundongos e coelhos resulta em uma contração com dois componentes distintos, o componente fásico ou "twiches" e o componente mais lento, o tônico. Essa resposta bifásica é devido ao processo de co-transmissão entre a noradrenalina e o ATP (Figura 6).

Figura 6: Esquema ilustrando o processo de co-transmissão entre noradrenalina e ATP promovendo a contração fásica e tônica das células musculares do DD (Burnstock, 1988).

A noradrenalina é responsável pelo componente tônico (lento) da contração. Ela é liberada por exocitose das vesículas neuronais, após a despolarização da membrana, de forma $\mathrm{Ca}^{2+}$ dependente, para o espaço extracelular. A noradrenalina ativa receptores metabotrópicos $\boldsymbol{\alpha}_{1}$-adrenérgicos ligados à proteína $G$ das células musculares do vaso deferente e promove a formação fosfolipase $\mathrm{C}(\mathrm{PLC})$ e de trifosfato de inositol $\left(\mathrm{IP}_{3}\right) . \mathrm{O}^{\mathrm{IP}} \mathrm{P}_{3}$ se liga aos receptores de membrana do retículo sarcoplasmático e promove a liberação de $\mathrm{Ca}^{2+}$ dos estoques. Parte da noradrenalina é rapidamente recaptada e metabolizada por enzimas intracelulares como a monoamino oxidase (MAO) e catecol-Ometiltransferase (COMT) (Koslov et al., 2013 apud Burnstock,1988).

O componente fásico ("twiches") é mediado pelo ATP, que após liberado para 
fenda sináptica, ativa receptores purinérgicos $\left(P_{2 \times 1}\right)$ promovendo a abertura de canais iônicos de $\mathrm{Ca}^{2+}$ e a entrada de $\mathrm{Ca}^{2+}$ para a célula. O ATP é rapidamente degradado e convertido em ADP, AMP e adenosina por ectonucleotidases.

O ATP e a noradrenalina podem agir também como neuromoduladores, atuando no mecanismo de feedback negativo via receptores $\mathrm{P}_{2 Y}$ e $\alpha_{2}$ dos neurônios interferindo desta forma na liberação dos mesmos pelo neurônio (Koslov et al., 2013 apud Burnstock,1988).

O aumento da concentração intracelular de íons $\mathrm{Ca}^{2+}$ promove a combinação deste com a proteína calmodulina e este complexo ativa a chamada miosinaquinase (MLC kinase), a qual irá fosforilar a cadeia de miosina e ocasionar a contração muscular. $\mathrm{O}$ aumento de $\mathrm{Ca}^{2+}$ citosólico aumenta a formação de proteína kinase $\mathrm{C}$ (PKC), que fosforila as proteínas alvo específicas. Finalmente, os canais de $\mathrm{Ca}^{2+}$ (canais de $\mathrm{Ca}^{2+}$ operados por voltagem) na membrana, também se abrem em resposta à despolarização da membrana provocada pelo estiramento da célula de músculo liso (Koslov et al., 2013 apud Burnstock, 1988).

Segundo Koslov et al. (2013) apud Burnstock,1988, as várias regiões do DD respondem de maneira diferente à estimulação de agonistas exógenos. A porção prostática responde mais ao ATP enquanto a porção epididimal responde mais à noradrenalina. Não foram demonstradas diferenças em relação à distribuição dos receptores $P_{2 \times 1}$ e $\alpha_{1}$ no DD de camundongos e ratos. No DD de camundongo, a diferença das respostas ao ATP, foi atribuída à baixa neuroliberação deste na porção epididimal. Terradas et al. (2001) confirmou que as duas porções do DD diferem na sensibilidade pós-sináptica à noradrenalina, análises de Western blot indicaram uma concentração menor de proteína $\mathrm{G}$ na porção prostática em relação à epididimal.

Além de receptores $\alpha_{1}$-adrenérgicos e purinérgicos, existem no Ducto deferente de rato (DDR) receptores $\beta$-adrenérgicos (Diaz-Toledo \& Jurkiewicz, 1991) e receptores para outros agonistas, como acetilcolina (Miranda et al., 1995), histamina (Vassilev et al., 1991), serotonina (Garcez-do-Carmo, 1995), neuropeptídio $Y$ (Donoso et al., 1988), dentre outros.

O DD possui entre outros, canais de $\mathrm{K}^{+}$que podem estar diretamente relacionados ao seu mecanismo de contração. Segundo experimentos realizados por Ohya et al. em 1997, os canais de $\mathrm{K}^{+}$são representados no DD pelas subunidades $\mathrm{K}_{\mathrm{v}} 1.4, \mathrm{~K}_{\mathrm{v}} 3.3, \mathrm{~K}_{\mathrm{v}} 3.4, \mathrm{~K}_{\mathrm{v}} 4.2$ e $\mathrm{K}_{\mathrm{v}} 4.3$. Em 2006, Teramoto ainda descreveu o papel dos canais de $\mathrm{K}^{+}$sensíveis a ATP, que também estão ligados ao mecanismo 
de contração das células musculares do DD.

Considerando suas características anatômicas, que permitem sua fácil manipulação bem como suas características funcionais, dotada de uma rica inervação simpática, o DD é um modelo muito utilizado para o estudo de mecanismos envolvidos com a neurotransmissão, transdução do sinal e a contração do tecido muscular liso. 


\section{OBJETIVO}

O objetivo do trabalho foi isolar, caracterizar e verificar o efeito biológico da crotamina do veneno de Crotalus durissus terrificus sobre a neurotransmissão adrenérgica e purinérgica e a sua possível ação sobre a contratilidade da musculatura lisa do ducto deferente de rato.

\subsection{Objetivos específicos}

- Isolar a crotamina por cromatografia;

- Determinar sua massa molecular e pureza;

- Estudar os efeitos da crotamina sobre a contração neurogênica (efeito pré-sináptico), induzida por concentração única de tiramina e por estimulação elétrica do DDR.

- Estudar os efeitos da crotamina sobre o componente pós-sináptico de contração, por meio de curva concentração-resposta de noradrenalina e concentração única de ATP no DDR.

- Comparar o efeito da crotamina com o de um bloqueador inespecífico de canais de $\mathrm{K}^{+}$, o tetraetilamônio (TEA), no ducto deferente de rato. 


\section{MATERIAIS E MÉTODOS}

\subsection{Infraestrutura}

O trabalho foi desenvolvido no Centro de Biotecnologia do IPEN/CNEN e em laboratórios de nossos parceiros científicos, citados na metodologia.

$O$ veneno de $C$. $d$. terrificus e também a crotamina isolada utilizados para os experimentos realizados neste trabalho foram gentilmente cedidos pelo Centro de Estudo de Venenos e Animais Peçonhentos - CEVAP, situado na cidade de Botucatu. Todos os reagentes utilizados na realização dos experimentos foram de qualidade pró-análise. A água utilizada para o preparo das soluções foi procedente de um sistema Milli $Q$.

Parte dos experimentos foi realizada no Laboratório de Farmacologia do Instituto Butantan (São Paulo/SP).

\subsection{Isolamento da crotamina}

\subsubsection{Cromatografia de Exclusão Molecular}

$\mathrm{O}$ isolamento das toxinas foi feito a partir do veneno de $C$. durissus terrificus, por cromatografia de exclusão molecular em coluna de gel filtração (Superdex ${ }^{\circledR} 75$ $-10 / 300 \mathrm{GL}$ ) em cromatógrafo äkta $\left(G E^{\circledR}\right.$ Life Science ${ }^{\circledR}$ ). A coluna de gel filtração foi ambientada em tampão formiato de amônio 200 mM, pH 3,0. Após a passagem de 3 volumes dE coluna, $500 \mu \mathrm{L}$ da amostra $(16 \mathrm{mg} / \mathrm{mL})$ foi então aplicado no mesmo fluxo de equilíbrio da coluna. O perfil cromatográfico obtido foi monitorado pela leitura da absorvância em $280 \mathrm{~nm}$ e foi registrado pelo próprio sistema. Os picos correspondentes à crotamina foram coletados, congelados e posteriormente liofilizados.

\subsubsection{Cromatografia de Troca lônica}

A fração correspondente à crotamina, já liofilizada, foi ressuspendida em tampão fosfato de sódio $50 \mathrm{mM}, \mathrm{pH}$ 7,8 (tampão A) e aplicada em uma resina do tipo Mono S (troca catiônica), em sistema HPLC, estabilizada no mesmo tampão. Após a adsorção da crotamina, esta foi eluída com gradiente linear de salina, de 0 a $2 \mathrm{M}$ de $\mathrm{NaCl}$ (tampão $\mathrm{A}+2 \mathrm{M}$ de $\mathrm{NaCl}$ ). Verificou-se a absorvância em $280 \mathrm{~nm}$ durante todo o processo cromatográfico. Posteriormente, a crotamina foi dialisada 13 
em membrana adequada (limite máximo de 3000 Da -SIGMA ${ }^{\circledR}$ ) contra água e de maneira exaustiva ( 3 trocas no volume de $2 \mathrm{~L}$ cada). Após a liofilização, a crotamina foi armazenada em freezer $\mathrm{a}-20^{\circ} \mathrm{C}$.

\subsubsection{Cromatografia de exclusão molecular de alta eficiência (HPSEC)}

A cada fase cromatográfica, foram aliquotados $200 \mu \mathrm{L}$ das frações de interesse (crotamina) para realização de cromatografia de exclusão molecular de alta eficiência em coluna de gel filtração analítica (Superdex ${ }^{\circledR} 75-10 / 300$ GL), conectada ao sistema de HPLC. Para a primeira análise, a coluna de gel filtração foi ambientada em tampão formiato de amônio 200 mM, pH 3,0. Após a passagem de 3 vezes o volume da coluna, cerca de $100 \mu \mathrm{L}$ da amostra foi então aplicado no mesmo fluxo de equilíbrio da coluna. O perfil cromatográfico obtido foi monitorado pela leitura da absorvância a $280 \mathrm{~nm}$ em um espectrofotômetro acoplado ao próprio sistema. Na segunda análise, as condições cromatográficas citadas acima foram mantidas, porém as alíquotas de $100 \mu \mathrm{L}$ de crotamina injetadas no sistema eram referentes à segunda etapa de isolamento. Neste caso, o perfil cromatográfico também foi acompanhado por medidas de absorvância a $280 \mathrm{~nm}$. Esta técnica analítica foi utilizada para verificação da pureza após cada fase cromatográfica.

\subsubsection{Cromatografia de Fase Reversa (RP-HPLC)}

A Cromatografia de fase reversa foi realizada com o intuito de analisar e comparar a crotamina cedida pelo CEVAP com o veneno total de Crotalus durissus terrificus e demonstrar através disso seu isolamento. Para a execução do método, utilizou-se uma coluna de fase reversa C-8. Inicialmente a coluna foi ambientada com $0,05 \%$ de ácido fórmico e após a injeção da amostra, passou-se um gradiente de 0 a $100 \%$ de acetonitrila para eluir a crotamina. Durante toda a corrida cromatográfica a leitura da absorvância foi monitorada a $280 \mathrm{~nm}$ em espectrofotômetro acoplado ao sistema.

\subsection{Determinação de massa molecular}

A pureza e massa molecular do peptídeo purificado foram determinadas por espectrometria de massas em um espectrômetro Shimadzu ${ }^{\circledR}$ LC-IT ToF no Laboratório de Bioquímica do Instituto Butantan. 


\subsection{Animais}

Foram utilizados 75 ratos Wistar machos com idade média de 4 a 5 meses e peso aproximadamente de $350 \mathrm{~g}$. Os ratos foram obtidos do Biotério Central do Instituto Butantan, mantidos em ambiente controlado (temperatura entre $23^{\circ} \mathrm{C}$ a $25^{\circ} \mathrm{C}$, ciclo de $12 / 12$ horas claro/escuro), recebendo água e alimento ad libitum. Os protocolos experimentais foram aprovados de acordo com Comitê de Ética do Instituto Butantan sob o número 1261/14.

\subsection{Experimentos de contração muscular "in vitro"}

\subsubsection{Isolamento dos ductos deferentes}

Os animais foram eutanasiados em câmara de $\mathrm{CO}_{2}$, para a retirada dos ductos deferentes. Após a eutanásia, a parede abdominal foi aberta para a retirada dos dois ductos deferentes, os quais foram colocados em líquido nutritivo Tyrode, com a seguinte composição iônica $(\mathrm{mM})$ : $\mathrm{NaCl}(138,0), \mathrm{KCl}(2,7), \mathrm{MgCl}_{2}(1,0), \mathrm{CaCl}_{2}$ $(1,4), \mathrm{NaH}_{2} \mathrm{PO}_{4}(0,36), \mathrm{NaHCO}_{3}(12,0)$, Glicose $(5,5)$. Com o auxílio de pinça e tesoura, os tecidos adjacentes (vasos sanguíneos e tecido adiposo) foram retirados e, com uma seringa, foi passado líquido nutritivo pela luz do órgão para a remoção da secreção interna. Após a limpeza, a porção prostática do órgão foi amarrada a uma linha e fixada a um transdutor isométrico (LSI LETICA ${ }^{\circledR}$ ). Para todos os experimentos, somente foi usada a porção prostática do DDR, por possuir uma maior sensibilidade ao componente neurogênico de contração. O ducto deferente contralateral foi usado como controle paralelo.

Os órgãos foram então montados em uma câmara de parede dupla (Hooker et al., 1977) constituídas por uma cuba de vidro, com volume de $5 \mathrm{~mL}$, preenchida por Tyrode e aerada constantemente com carbogênio $\left(95 \% \mathrm{O}_{2}\right.$ e $\left.5 \% \mathrm{CO}_{2}\right)$, com circulação externa de água a $37^{\circ} \mathrm{C}$. Os sinais dos transdutores de força, gerados pela contração isométrica do músculo liso, foram enviados a um amplificador (ETH400 Bridge Amplifier), passando a seguir ao equipamento de aquisição de dados (Powerlab $\left.{ }^{\circledR} / 4 S P\right)$, o qual está acoplado a um microcomputador. O programa de computador Chart ${ }^{\circledR}$ 4.2 foi utilizado para o registro e a análise de dados.

\subsubsection{Protocolos experimentais}

Uma vez ajustada a aparelhagem, o DD ficou em repouso por cerca de 45 
minutos, sendo lavado a cada 15 minutos para a estabilização da preparação. Em todos protocolos, após o período de estabilização, foi inicialmente adicionada ao banho, uma concentração única máxima de cloreto de potássio $(80 \mathrm{mM})$ para servir de referência como efeito máximo da preparação. Em seguida foram iniciados os protocolos experimentais.

\subsubsection{Estudo da capacidade de liberação de neurotransmissores}

O estudo da capacidade de neuroliberação de transmissores foi realizado por estimulação elétrica do tecido na ausência (controle) e na presença da crotamina.

\section{Contrações isométricas induzidas por estimulação elétrica}

A amplitude da contração obtida para cada frequência foi medida em gramas de tensão do ducto deferente. Para as frequências a partir de $1 \mathrm{~Hz}$ foram considerados para análise os resultados dos componentes fásico e tônico de contração. Os ductos deferentes foram estimulados eletricamente a uma voltagem supramáxima, de $70 \mathrm{~V}$ com 3 ms de duração, nas frequências de 0,05, 1, 5, 10 e 20 $\mathrm{Hz}$, parâmetros esses que estimulam somente o tecido neuronal. A contração causada por cada frequência (exceto $0,05 \mathrm{~Hz}$ ) foi registrada por 30 segundos, com 10 minutos de intervalo entre os estímulos.

A contração obtida com a frequência de $0,05 \mathrm{~Hz}$ se apresenta na forma de "twitches", denominada contração fásica. Com frequências mais altas (1, 5, 10, 20 $\mathrm{Hz}$ ) a contração se torna mais intensa e com característica bifásica, com um componente rápido inicial (fásico) seguido de um componente tônico de instalação mais lenta. A figura 7 mostra um registro típico das contrações obtidas nessas frequências.

Figura 7 - Registro típico da contração do ducto deferente de rato, induzida pela estimulação elétrica em frequências crescentes entre 0,05 a $20 \mathrm{~Hz}(50 \mathrm{~V}, 3 \mathrm{~ms})$.

\section{Contrações isométricas induzidas por concentração única de tiramina}

O presente ensaio foi realizado também na presença de tetraetilamônio (TEA) na concentração de $1000 \mathrm{mM}$, um bloqueador de canais de $\mathrm{K}^{+}$inespecífico com o intuito de comparar seu efeito com o efeito da crotamina sobre a contração causada pela tiramina. 
Após o período de estabilização da preparação ( $\pm 30 \mathrm{~min})$, foi adicionada ao banho tiramina em concentração única de $10^{-4} \mathrm{M}$. A contração foi registrada até ser atingido o efeito máximo, sendo a preparação lavada logo em seguida. A amplitude da contração induzida pela tiramina foi medida em gramas de tensão.

\subsubsection{Avaliação da reatividade pós-sináptica}

\section{Curva concentração-efeito cumulativa de noradrenalina}

Foram efetuadas curvas concentração-efeito cumulativas de noradrenalina (agonista a-adrenoceptores) segundo a técnica de Van Rossum (1963). Após ser atingido o efeito máximo do agonista, a preparação foi lavada com líquido nutritivo e deixada em repouso por 30 minutos quando então foi iniciada uma nova curva. Em cada preparação foram realizadas no máximo 3 curvas concentração-efeito, sendo que a última curva foi realizada na presença e na ausência (controle) da crotamina, previamente encubada por 30 minutos e consideradas para análise de resultados. A amplitude de contração induzida por cada concentração de noradrenalina foi medida em gramas de tensão.

Este ensaio foi realizado também na presença de tetraetilamônio (TEA) em três diferentes concentrações (100, 300 e $1000 \mathrm{mM})$, com o intuito de comparar seu efeito com o efeito da crotamina sobre a contração causada pela noradrenalina.

\section{Dose única de ATP}

Foram realizados estímulos por dose única de adenosina trifosfato (ATP, 10${ }^{4} \mathrm{M}$ ) na ausência (controle) e na presença de crotamina $(1 \mu \mathrm{g} / \mathrm{mL})$ ou TEA (1000 mM). A amplitude de contração foi medida em porcentagem em relação ao efeito máximo promovido pelo $\mathrm{KCl}(80 \mathrm{Mm})$.

Os estímulos com ATP foram realizados também na presença de tetraetilamônio (TEA), além de crotamina, com o intuito de comparar seus efeitos sobre a contração causada pela tiramina.

\subsection{Parâmetros farmacológicos}

3.6.1 Efeito máximo $\left(E_{\max }\right)$ 
$O E_{\max }$ atingido por concentrações únicas dos diferentes agonistas (tiramina, ATP e noradrenalina) ou por estímulo elétrico foi obtido diretamente a partir das medidas de contração da musculatura realizadas no ducto deferente.

3.6.2 Afinidade aparente do agonista ( $p D 2)$

O parâmetro pD2 por definição representa o valor negativo do logaritmo da concentração do agonista que produz $50 \%$ do efeito máximo (ED50) de curvas concentração-efeito cumulativas, segundo a fórmula (ARIENS, 1954):

pD2 $=-\log$ de ED50

\subsection{Análise estatística}

Os dados foram apresentados como média \pm erro padrão da média. As diferenças de médias dos resultados obtidos foram comparadas por a análise de variância (ANOVA), seguida do teste de Tukey. O teste "t" de Student foi usado para a análise de dados paramétricos de amostras pareadas e não pareadas. A probabilidade de $p \leq 0,05$ foi considerada estatisticamente significante. 


\section{RESULTADOS}

A seguir serão apresentados os resultados referentes ao fracionamento do veneno total da $C$. $d$. terrificus para obtenção da crotamina isolada.

\subsection{Isolamento da crotamina}

A Figura 8 apresenta o perfil cromatográfico da primeira etapa de fracionamento (exclusão molecular) do veneno total da $C$. $d$. terrificus. O primeiro pico indica a fração correspondente à convulxina, o segundo pico é correspondente à delta-toxina, a giroxina está representada pelo terceiro pico, o quarto pico corresponde à crotoxina e o indicado é a fração da crotamina. Os picos eluídos após a crotamina possivelmente representam a fração analgésica e os tripeptídeos, respectivamente. $\mathrm{O}$ pico apontado na Figura 8 representa a crotamina que é o objeto de interesse neste trabalho.

Cabe ressaltar que o perfil cromatográfico apresentado na Figura 8 não ilustra claramente o pico 2, corresponde à delta toxina. Vital Brazil (1980) sugeriu a existência de uma toxina que eluiria entre a convulxina e a giroxina quando o veneno é fracionado por cromatografia de exclusão molecular e que estaria envolvida na agregação plaquetária, alteração da permeabilidade vascular e capaz de causar grande hemoconcentração. Análises mais recentes, com resinas de maior resolução, permitiram a observação e o estudo do pico da delta toxina (Campos, 2006), porém mudanças na técnica cromatográfica aplicada, como tampão e fluxo de corrida, podem influenciar diretamente a separação das proteínas, especialmente as de alta massa molecular. Assim, embora a literatura descreva a presença da delta toxina entre os picos 1 e 3 , convulxina e giroxina respectivamente, não foi possível observar relevância em tal região diante dos parâmetros utilizados para esta análise cromatográfica inicial.

Figura 8: Cromatograma do veneno total da Crotalus durissus terrificus em coluna de exclusão molecular Superdex 75 10/300 GL. O tampão formiato de amônio, 200 $\mathrm{mM}, \mathrm{pH} 3,0$ foi utilizado para a eluição das frações. Em cada análise foram injetados $10 \mathrm{mg}$ de veneno total dissolvido em $600 \mu \mathrm{L}$ de tampão formiato de amônio. Os picos correspondem à convulxina (pico 1), delta-toxina (pico 2), giroxina (pico 3), crotoxina (pico 4), crotamina (pico 5 indicado pela seta), analgésico (pico 6) e tripeptídeos (pico 7). 
Após cada etapa cromatográfica, foi realizada uma cromatografia analítica em coluna de gel filtração (Superdex 75 10/300 GL) com o objetivo de avaliar o grau de pureza da amostra de interesse. Assim, foram coletados $200 \mu \mathrm{L}$ dos tubos $11 \mathrm{e}$ 12 , referentes à crotamina nativa após a primeira e a segunda etapa cromatográfica para estudo analítico (Figura 9). Pode-se observar que o volume de eluição (15,29 $\mathrm{mL}$ ) ficou muito próximo daquele obtido na Figura $8(15,37 \mathrm{~mL})$, confirmando assim que o pico majoritário corresponde à toxina de interesse. Por meio da integração do perfil cromatográfico foi possível verificar que o pico correspondente à crotamina representou aproximadamente $89 \%$ da área total. De acordo com o perfil, fica evidente que ainda existem outros componentes nesse pool referente à crotamina e, portanto, se faz necessária mais uma etapa de fracionamento.

Figura 9: Perfil cromatográfico da gel filtração analítica da fração correspondente à crotamina oriunda da primeira etapa de fracionamento (Figura 8) A coluna Superdex 75 10/300 GL (24 mL) foi ambientada em tampão formiato, $200 \mathrm{mM}, \mathrm{pH} 3,0$. O volume aplicado foi de $200 \mu \mathrm{L}$. A seta indica o pico corresponde à crotamina.

A Figura 10 ilustra o segundo passo cromatográfico da crotamina (pico 5 da Figura 8), em coluna de troca catiônica do tipo Mono S. O gradiente linear de $\mathrm{NaCl}$ utilizado para eluição da fração de interesse variou de 0 a $2 \mathrm{M}$. $\mathrm{O}$ ombro observado no pico correspondente à crotamina indica, provavelmente, a presença de isoformas para esta toxina (Toyama et al., 2000).

Figura 10: Recromatografia da crotamina em coluna de troca catiônica (Mono S). Utilizou-se tampão fosfato de sódio, $50 \mathrm{mM}, \mathrm{pH} 7,8$. O gradiente linear de $\mathrm{NaCl}$ variou de 0 a $2 \mathrm{M}$.

Na Figura 11 está representado o cromatograma da gel filtração analítica da crotamina após a segunda etapa de isolamento. O pico correspondente à toxina foi eluído em volume muito próximo daquele obtido na primeira etapa de isolamento e representou $98 \%$ do cromatograma total, indicando que a crotamina foi isolada de forma efetiva para o propósito deste trabalho.

Figura 11: Gel filtração analítica da fração correspondente à crotamina após a segunda etapa de isolamento (Figura 10). A coluna Superdex $75(24 \mathrm{~mL})$ foi ambientada em tampão formiato de amônio, 200 mM, pH 3,0. 


\subsection{Análise da crotamina por Cromatografia de Fase Reversa}

Como critério adicional de pureza, submeteu-se a crotamina e o veneno total da Crotalus durissus terrificus à análise cromatográfica de Fase reversa em coluna de fase reversa C-8 ambientada com 0,05\% de ácido fórmico e após a injeção da amostra, passou-se um gradiente de 0 a $100 \%$ de acetonitrila para eluir a crotamina. A leitura da absorvância foi monitorada a $280 \mathrm{~nm}$ em espectrofotômetro acoplado ao sistema (Figura 12).

Figura 12: Cromatograma do veneno total da Crotalus durissus terrificus em coluna de Fase Reversa. A coluna C-8 foi ambientada com 0,05\% de ácido fórmico e, após a injeção da amostra, passou-se um gradiente de 0 a $100 \%$ de acetonitrila. A leitura da absorvância foi monitorada a 280nm.

A Figura 13 representa o cromatograma da fase reversa analítica da crotamina (CEVAP).

Figura 13: Cromatograma da crotamina proveniente do CEVAP em coluna de Fase Reversa. A coluna C-8 foi ambientada com 0,05\% de ácido fórmico e após a injeção da amostra, passou-se um gradiente de 0 a $100 \%$ de acetonitrila para a eluição. A leitura da absorvância foi monitorada a 290nm.

Na Figura 14 está representada a sobreposição da crotamina (vermelho) cedida pelo CEVAP e o veneno total da Crotalus durissus terrificus (azul). Como esperado, o pico correspondente à toxina foi eluído em volume muito próximo daquele correspondente à crotamina no veneno total, comprovando sua identidade.

Figura 14: Sobreposição entre os cromatogramas do Veneno total de Crotalus durissus terrificus (azul) e a crotamina (vermelho) em coluna de Fase Reversa. A coluna C-8 foi ambientada com $0,05 \%$ de ácido fórmico e, após a injeção da amostra, passou-se um gradiente de 0 a $100 \%$ de acetonitrila. A leitura da absorvância foi monitorada a 280nm.

\subsection{Determinação de massa molecular}

Como critério adicional de identidade e pureza, a crotamina foi por espectrometria de massa (eletrospray). Na Figura 15, é possível verificar os envelopes de massa detectados. Na Figura 16 é possível observar o o envelope majoritário $(\mathrm{m} / \mathrm{z}=814,8607)$ que corresponde ao íon com carga +6 cuja massa foi 
calculada em 4883,1642 Da. Observamos também uma isoforma ( $\mathrm{m} / \mathrm{z}=790,8550$; $z=+6)$ cuja massa é 4739,13 Da.

Figura 15: Espectro de massa da crotamina analisada por infusão direta.

Figura 16: Zoom do pico majoritário para determinação do estado de carga.

Foi possível observar a presença de uma aparente isoforma da crotamina (Figura 17).

Figura 17: Espectro indicando a presença de uma possível isoforma de crotamina.

Na Figura 18 é possível observar o pico minoritário, uma isoforma da crotamina.

Figura 18: Zoom do pico minoritário para determinação do estado de carga.

\subsection{Ensaios biológicos}

\subsubsection{Analise da neurotransmissão}

4.4.1.1 Curva dose resposta de crotamina em contrações induzidas por EE (estimulação elétrica) de baixa frequência $(0,05 \mathrm{~Hz})$

Com o intuito de analisar o efeito pré-sináptico da crotamina no ducto deferente de rato (DDR), ou seja, sua influência na liberação de neurotransmissores, foi realizada uma curva dose resposta com diferentes doses da toxina com estimulação elétrica de baixa frequência $(0,05 \mathrm{~Hz})$. Os sinais gerados pela contração isométrica do músculo liso, foram enviados a um amplificador (ETH400 Bridge Amplifier), e a aquisição de dados foi feita por meio do Powerlab ${ }^{\circledR} / 4 S P$, acoplado a um microcomputador, e o registro foi realizado pelo programa Chart ${ }^{\circledR} v$ 4.2. A amplitude da contração obtida para cada frequência foi medida em gramas de tensão do ducto deferente.

A contração foi induzida por estimulação elétrica nos ductos deferentes em tensão de $70 \mathrm{~V}$ com $3 \mathrm{~ms}$ de duração e frequência de $0,05 \mathrm{~Hz}$, a contração obtida 
nessa frequência se apresenta na forma de 'twitches', denominada contração fásica. Após estabilização por cerca de 30 minutos, a crotamina nas concentrações crescentes de $0,1 \mu \mathrm{g} / \mathrm{ml}, 0,5 \mu \mathrm{g} / \mathrm{ml}$ e $1 \mu \mathrm{g} / \mathrm{ml}$ adicionada ao banho em intervalos de $30 \mathrm{~min}$.

Nos registros da Figura 19 é possível observar o momento em que a crotamina $(0,1 \mu \mathrm{g} / \mathrm{mL})$ é adicionada. No primeiro registro $(A)$ a diminuição da contratilidade do DDR é observada no momento em que a crotamina é adicionada enquanto que no registro do controle $(B)$, onde não foi adicionada a crotamina, nenhuma mudança foi observada.

A

B

Figura 19: Registros (Powerlab/4SP) de contração em que o DDR foi submetido à baixa frequência, na presença de crotamina $(0,1 \mu \mathrm{g} / \mathrm{mL})(A)$, e controle $(B)$.

O gráfico a seguir (Figura 20), ilustra o efeito da crotamina nestas diferentes concentrações na contração do DDR. É possível observar uma diminuição da contração do DDR após a incubação com a crotamina. Este efeito foi mais expressivo, verificado nas concentrações de 0,1 e $0,5 \mu \mathrm{g} / \mathrm{ml}$ de crotamina $(95,7 \pm 4,6 \%$ e $85,4 \pm 5,9 \%$, respectivamente) enquanto que na dose de $1 \mu \mathrm{g} / \mathrm{mL}$ de crotamina este efeito não foi significativo.

Figura 20: Amplitude das contrações fásicas induzidas por estimulação elétrica em baixa frequência $(0,05 \mathrm{~Hz})$ em DDR, na ausência (controle) e na presença de diferentes doses de crotamina $(0,1 \mu \mathrm{g} / \mathrm{ml}, 0,5 \mu \mathrm{g} / \mathrm{ml}$ e $1 \mu \mathrm{g} / \mathrm{ml})$. Cada ponto representa a média \pm e.p.m. de 6 experimentos.

*Valores de $\mathrm{P} \leq 0,05$.

\subsubsection{Curva de frequência}

O DDR foi submetido a uma curva de frequência com diferentes doses de crotamina $(0,1 \mu \mathrm{g} / \mathrm{mL}, 0,5 \mu \mathrm{g} / \mathrm{mL}$ e $1 \mu \mathrm{g} / \mathrm{mL})$. A amplitude da contração obtida para cada frequência foi medida em gramas de tensão. Para as frequências a partir de 1 $\mathrm{Hz}$ foram considerados para análise os resultados dos componentes fásico e tônico de contração. Os ductos deferentes foram estimulados eletricamente a uma voltagem supramáxima, de $70 \mathrm{~V}$ com $3 \mathrm{~ms}$ de duração, nas frequências de 1, 5, 10 
e $20 \mathrm{~Hz}$, parâmetros esses que estimulam somente o tecido neuronal. A contração causada por cada frequência foi registrada por 30 segundos, com 10 minutos de intervalo entre os estímulos.

Observa-se a curva de frequência realizada no DDR na presença e ausência de crotamina onde é possível visualizar o aumento da contração à medida que se aumenta a frequência (Figura 21 A e B).

Figura 21: Registro (Powerlab/4SP) de contrações da curva de frequência $(1 \mathrm{~Hz}$, $5 \mathrm{~Hz}, 10 \mathrm{~Hz}$ e $20 \mathrm{~Hz}$ ) em que o DDR foi submetido, na ausência (A) e incubado com crotamina (B).

\subsubsection{Componente fásico de contração}

O gráfico a seguir (Figura 22) representa a amplitude do componente de contração fásica induzida por estimulação elétrica na porção prostática do DDR.

Figura 22: Amplitude das contrações fásicas induzidas por estimulação elétrica em frequências crescentes $(1 \mathrm{~Hz}, 5 \mathrm{~Hz}, 10 \mathrm{~Hz}$ e $20 \mathrm{~Hz})$ em DDR, na ausência (controle) e na presença de diferentes doses de crotamina $(0,1 \mu \mathrm{g} / \mathrm{ml}, 0,5 \mu \mathrm{g} / \mathrm{ml}$ e $1 \mu \mathrm{g} / \mathrm{ml})$. Cada ponto representa a média \pm e.p.m. *Valores de $\mathrm{P} \leq 0,05$. (N!=6)

É possível observar um aumento significativo $(3,2 \pm 0,2 \mathrm{~g})$ da contração na presença de crotamina na concentração de $1 \mu \mathrm{g} / \mathrm{mL}$ em relação ao controle $(2,2 \pm 0,2 \mathrm{~g})$ na frequência de $20 \mathrm{~Hz}$. Nas concentrações de 0,1 e 0,5 $\mu \mathrm{g} / \mathrm{de}$ crotamina, existe uma tendência à diminuição da amplitude da contração.

\subsubsection{Componente tônico de contração}

O gráfico a seguir (Figura 23) representa a curva do componente tônico da contração do DDR. A figura apresenta uma tendência à diminuição da contratilidade com as doses de 0,1 e 0,5 $\mu \mathrm{g} / \mathrm{mL}$ de crotamina. Na estimulação em $10 \mathrm{~Hz}$ a crotamina $(0,1 \mu \mathrm{g} / \mathrm{mL})$ causou uma diminuição estatística da contração $(0,9 \pm 0,2 \mathrm{~g})$ em relação ao controle $(1,6 \pm 0,1 \mathrm{~g})$.

Figura 23: Amplitude das contrações tônica induzidas por estimulação elétrica em frequências crescentes $(1 \mathrm{~Hz}, 5 \mathrm{~Hz}, 10 \mathrm{~Hz}$ e $20 \mathrm{~Hz})$ em DDR, na ausência (controle) e na presença de diferentes doses de crotamina $(0,1 \mu \mathrm{g} / \mathrm{ml}, 0,5 \mu \mathrm{g} / \mathrm{ml}$ e $1 \mu \mathrm{g} / \mathrm{ml})$. Cada ponto representa a média \pm e.p.m. de 6 experimentos.

\subsubsection{Contrações isométricas induzidas por concentração única de}




\section{tiramina}

A tiramina é um simpatomimético indireto que tem a capacidade de estimular a liberação de grandes quantidades de catecolaminas armazenadas nos terminais nervosos por meio da reversão do processo de receptação (Berg \& Jensen, 2013). Dessa forma, a tiramina foi utilizada como modelo de contração por neuroliberação. A tiramina foi capaz de promover a uma contração lenta e sustentada da musculatura do DDR, que foi medida em gramas de tensão. A concentração de crotamina (1 $\mu \mathrm{g} / \mathrm{mL})$ não interferiu significativamente na contração promovida pela tiramina $(1,1 \pm 0,1 \mathrm{~g})$ em relação ao controle $(0,9 \pm 0,1 \mathrm{~g})$ enquanto que, na presença de TEA $(1000 \mathrm{mM})$ houve um aumento na contração $(1,4 \pm 0,2 \mathrm{~g})$ em relação ao grupo controle (Figura 24).

Figura 24: O histograma representa a contração do DDR, proporcionada por concentração única de tiramina $\left(10^{-4} \mathrm{M}\right)$ na ausência (controle) e na presença e de crotamina $(1 \mu \mathrm{g} / \mathrm{mL})$ ou TEA $(1000 \mathrm{mM})$. Cada ponto representa a média \pm e.p.m. de 6 experimentos

*Valores de $\mathrm{P} \leq 0,05$

\subsection{Estudo do componente pós sináptico de contração}

\subsubsection{Curva dose-resposta (CDR) - Noradrenalina}

Foram efetuadas curvas concentração-efeito cumulativas de noradrenalina. Após ser atingido o efeito máximo do agonista, a preparação foi lavada com líquido nutritivo e deixada em repouso por 30 minutos quando então foi iniciada uma nova curva. Em cada preparação foram realizadas no máximo 3 curvas concentraçãoefeito, sendo que a última curva foi realizada na presença e na ausência (controle) da crotamina, previamente encubada por 30 minutos e consideradas para análise de resultados. A amplitude de contração induzida por cada concentração de noradrenalina foi medida em gramas de tensão.

A Figura 25 representa a curva dose resposta realizada na porção prostática do DDR na presença de crotamina doses $(0,1 \mu \mathrm{g} / \mathrm{mL}, 0,5 \mu \mathrm{g} / \mathrm{mL}$ e $1 \mu \mathrm{g} / \mathrm{mL})$ e na ausência (controle). Os parâmetros farmacológicos analisados, como efeito máximo $E_{\max }$ e $\mathrm{O} \mathrm{pD}_{2}$ não se mostraram diferentes quando comparado ao grupo controle (TABELA 2) em todas concentrações estudadas. 
Figura 25: Curva concentração resposta cumulativa de noradrenalina, na ausência (controle) e na presença de crotamina em diferentes doses $(0,1 \mu \mathrm{g} / \mathrm{mL}, 0,5 \mu \mathrm{g} / \mathrm{mL}$ e $1 \mu \mathrm{g} / \mathrm{mL}$ ). Os pontos representam a média \pm e.p.m., a amplitude de contração foi medida em gramas de tensão (N!=8).

TABELA 2 - Representa os valores de contração em gramas de tensão expressos em média \pm erro padrão do efeito máximo $\left(E_{\max }\right)$ e do $\mathrm{pD}_{2}$, extraídos da curva concentração resposta de noradrenalina na ausência e na presença de crotamina.

\begin{tabular}{cccc}
\hline & & & \\
& & $\mathrm{pD}_{2}$ & $\mathrm{E}_{\max }$ \\
\hline CONTROLE & & $5.44 \pm 0,10$ & $0,92 \pm 0,03$ \\
\hline & $0,1 \mu \mathrm{g} / \mathrm{ml}$ & $5,37 \pm 0,11$ & $1,02 \pm 0,04$ \\
CROTAMINA & $0,5 \mu \mathrm{g} / \mathrm{ml}$ & $5,36 \pm 0,14$ & $0,99 \pm 0,05$ \\
(N!=8) & $1 \mu \mathrm{g} / \mathrm{ml}$ & $5,22 \pm 0,14$ & $0,824 \pm 0,04$ \\
\cline { 2 - 4 } & & &
\end{tabular}

Com o intuito de comparar o efeito pós-sináptico da crotamina com um já conhecido bloqueador de canais de $\mathrm{K}^{+}$inespecífico, o TEA, a CDR foi realizada seguindo o mesmo protocolo também na presença deste (Figura 26, Tabela 3).

Figura 26: Curva concentração resposta de noradrenalina na ausência (controle) e na presença de TEA em diferentes doses (100mM, 300mM e $1000 \mathrm{mM})$. Os pontos representam a média \pm e.p.m., a amplitude de contração medida em gramas de tensão de 8 experimentos.

*Valores de $\mathrm{P} \leq 0,05$

TABELA 3 - Representa valores expressos em média \pm erro padrão da média do $\mathrm{pD}_{2}$ e Efeito máximo extraídos da curva concentração resposta de noradrenalina na ausência e na presença de TEA.

$\mathrm{pD}_{2} \quad \mathrm{E}_{\max }$

\begin{tabular}{cccc}
\hline CONTROLE & & $5,91 \pm 0,15$ & $1,17 \pm 0,05$ \\
\hline & $100 \mathrm{mM}$ & $5.84 \pm 0,11$ & $1,38 \pm 0,09$ \\
TEA & $300 \mathrm{mM}$ & $5,61 \pm 0,29$ & $1,86 \pm 0,20^{*}$ \\
& $1000 \mathrm{mM}$ & $6,02 \pm 0,50$ & $2,51 \pm 0,35^{*}$ \\
*Valor de $\mathrm{P} \leq 0,05 .(\mathrm{N} !=8)$ & &
\end{tabular}


De acordo com a figura e com os valores da Tabela 3, o efeito máximo da noradrenalina foi potencializado na presença de TEA nas concentrações de $300 \mathrm{mM}$ $(1,9 \pm 0,2 \mathrm{~g})$ e $1000 \mathrm{mM}(2,5 \pm 0,4 \mathrm{~g})$ em relação ao grupo controle $(1,2 \pm 0,1)$. Não houve alteração nos valores de pD2 em todas as concentrações de TEA observadas.

\subsubsection{Dose única de ATP}

As contrações induzidas pela concentração única de ATP $\left(10^{-3} \mathrm{M}\right)$, foram realizadas na ausência (controle) e presença de crotamina $(1 \mu \mathrm{g} / \mathrm{mL}$ ) ou TEA (1000mM) e a amplitude de contração foi medida em porcentagem em relação ao efeito máximo promovido pelo $\mathrm{KCl}(80 \mathrm{mM})$. O ATP provomeu uma amplitude de contração em cerca de $25 \%$ (grupo controle) em relação ao $\mathrm{KCl}$. Nos parametros utilizados em nossos experimentos, não observamos diferenças com relação a contração máxima provida pela crotamina $(27 \pm 3,7 \%)$ em relação ao controle $(25 \pm 3,5 \%)$. Contudo, como esperado, o TEA potencializou $(61 \pm 9,8 \%)$ a contração induzida pelo concentração única de ATP (Figura 27).

Figura 27 - Histograma representa o efeito máximo causado por concentração única de ATP $\left(10^{-3} \mathrm{M}\right)$ em DDR na ausência (controle) e na presença de crotamina $(1,0 \mu \mathrm{g} / \mathrm{ml})$ ou TEA $(1000 \mathrm{mM})$. A amplitude de contração foi medida em porcentagem em relação ao efeito máximo proporcionado por dose única de $\mathrm{KCl} 80 \mathrm{mM}$. Cada barra representa a média \pm e.p.m. de 6 experimentos.

*Valores de $\mathrm{P} \leq 0,05$ em relação ao controle. 


\section{DISCUSSÃO}

O gênero Crotalus é bem conhecido pela expressiva letalidade do seu veneno em acidentes ofídicos, sendo seus componentes uma fonte importante de substâncias bioativas de grande interesse toxinológico e farmacológico. O veneno crotálico é caracterizado por possuir efeitos neurotóxico, nefrotóxico, miotóxico, antitrombolítico, anti-plaquetário e analgésico (Chang et al., 1998; Toyama et al., 2006; Mancin, et al., 1998; Evangelista, et al.,2008).

A crotamina, um dos componentes do veneno crotálico, é uma toxina descrita como tendo ação capaz de despolarizar e contrair a musculatura esquelética. Em estudos de eletrofisiologia, Hong \& Chang (1983) creditaram tal efeito ao aumento do influxo de $\mathrm{Na}^{+}$na musculatura esquelética. Mais tarde, foi descrito que a crotamina teria ação sobre esses canais de maneira indireta (Matavel et al., 1998; Rizzi et al., 2007;). Em 2009, Yount et al. propuseram que a crotamina poderia agir bloqueando canais de $\mathrm{K}^{+}$voltagem-dependente, baseados na proximidade da estrutura tridimensional entre a crotamina e as $\beta$-defensinas humanas, cuja ação bloqueadora de canais de $\mathrm{K}^{+}$já estava descrita. Além disso, outra atividade descrita da crotamina é um aumento na liberação basal de acetilcolina (ACh) na musculatura esquelética (Hernandez Oliveira et al.,2013) no sistema nervoso central de ratos (Camillo et al., 2001). Esses dados indicam sua notória ação na musculatura estriada esquelética, contudo, pouco ou nenhum estudo foi realizado na musculatura lisa até o momento.

Com o intuito de compreender melhor o modo de ação dessa toxina e verificar se esta também modula a atividade de musculatura lisa, foi utilizado o ducto deferente de rato como modelo experimental. O DD é um dos órgãos periféricos mais densamente inervado pelo sistema nervoso autônomo simpático (Batra, 1974), fato que o torna uma importante ferramenta para estudos que envolvam a neurotransmissão e a ação de drogas noradrenérgicas.

Para dar início ao estudo, o veneno total da C. d. terrificus foi submetido a técnicas cromatográficas com o objetivo de isolar a crotamina. A primeira etapa realizada no fracionamento do veneno bruto foi a cromatografia de exclusão molecular, baseada no tamanho das moléculas dos componentes, onde foi possível observar a separação de 7 frações: convulxina (pico 1), delta-toxina (pico 2), giroxina (pico 3), crotoxina (pico 4), crotamina (pico 5), analgésicos e tripeptídeos (Picos 6 e 7). Atualmente, colunas que fornecem cromatogramas com maior resolução, permitem a verificação de um número maior de componentes, a exemplo 
dos picos 6 e 7 observados na Figura 8. Observou-se ainda que o pico 5, referentes à crotamina, foi o segundo mais representativo de todo o perfil cromatográfico. Estes dados corroboram com os achados de Slotta \& Fraenkel-Conrat (1938), Gonçalves \& Arantes (1956) e ainda trabalhos mais recentes (Boni-Mitake, 2000).

Após cada etapa de fracionamento do veneno crotálico foram realizadas cromatografias analíticas em coluna de gel filtração para verificar a eficiência dos processos de isolamento. A análise do pico correspondente à crotamina fracionada por gel-filtração deixa evidente que, a crotamina ainda não está totalmente isolada, como observado na Figura 9, onde foi verificado por meio da integração do perfil cromatográfico obtido que, o pico correspondente à toxina de interesse representou cerca de $89 \%$ da área total do cromatograma. Dois outros picos foram observados nesse caso e ambos apareceram depois do pico referente à crotamina (eluídos em maior volume), o que sugere componentes de menor volume hidrodinâmico, ou seja, peptídeos presentes no veneno da Crotalus durissus terrificus. Assim, uma segunda etapa cromatográfica foi realizada para a obtenção da toxina com alto grau de homogeneidade. Dessa forma, utilizamos uma cromatografia de troca catiônica para a obtenção de um maior grau de pureza da toxina. Para esta etapa cromatográfica, a crotamina deve adquirir uma configuração eletrônica positiva, estando portanto, em um tampão com pH menor do que o pl da proteína. Com base na Figura 10 foi possível verificar que o pico da crotamina mostrou-se assimétrico, ou seja, ocorreu a formação de um "ombro", especialmente na parte descendente do pico. Estes dados reforçam a ideia da existência de isoformas da crotamina, uma vez que, se partiu de um "pool" de veneno total da $C$. $d$. terrificus onde coexistem isoformas da toxina.

Isoformas protéicas podem ser resultado da mudança de um único aminoácido na sequência primária da proteína. Toyama et al. (2000) isolaram, por meio de um único passo de RP-HPLC, isoformas denominadas F2 e F3, cujas estruturas terciárias mostraram-se idênticas, diferindo em um ou dois aminoácidos apenas. Ambas as isoformas produziram paralisia espástica em camundongos e apresentaram a mesma DL50 (0,5 mg/kg de camundongo). Oliveira et al. (2010) também observou a presença de dois picos na cromatografia de fase reversa realizada em amostra de crotamina purificada a partir do veneno total de $C$. $d$. terrificus.

A análise em gel filtração analítica citada acima também foi reproduzida com a crotamina após a segunda etapa cromatográfica (troca iônica) e posteriormente ao processo de diálise (Figura 11). Nesse caso, o pico predominante correspondente à 29 
crotamina, que representou cerca de $98 \%$ da área total do perfil cromatográfico. Estes resultados mostraram que, as duas etapas de fracionamento do veneno crotálico utilizadas para o isolamento da crotamina foram extremamente satisfatórias considerando o propósito do trabalho.

A crotamina resultante desse processo de purificação foi utilizada nos experimentos em órgão isolado e com o intuito de confirmar as nossas observações, repetimos os experimentos com crotamina purificada obtida de fonte externa, cedida pelo CEVAP.

A fim de analisar e comparar a crotamina cedida pelo CEVAP com o veneno total de Crotalus durissus terrificus e demonstrar através disso sua pureza, realizouse uma cromatografia de fase reversa (RP-HPLC). Nesta técnica cromatográfica os componentes são separados pela hidrofobicidade, sendo que, aqueles de maior polaridade (menos hidrofóbicos) são eluídos primeiramente. Nas Figuras 12 e 13 observou-se o perfil cromatográfico do veneno total de Crotalus durissus terrificus e da crotamina, respectivamente, obtidos na fase reversa em coluna C-8, com 0,05\% de ácido fórmico e gradiente de acetonitrila. Como esperado, o pico correspondente à toxina foi eluído em volume muito próximo daquele correspondente à crotamina no veneno total, comprovando sua identidade (Figura 14).

A pureza e a massa molecular da crotamina foram comprovadas também por espectrometria de massas (Figuras 15, 16 e 17), onde foi observado a presença de duas isoformas de crotamina (Figuras 17 e 18). O envelope majoritário, como esperado, confirmou a identidade da crotamina demonstrando massa molecular de 4883,1642 Da, como descrito (Laure, 1975).

Após verificar a identidade e a pureza da crotamina, os ensaios em órgão isolado foram iniciados utilizando a porção prostática do DDR como modelo experimental por ter uma inervação adrenérgica mais densa que a porção epididimal (Koslov, 2013).

Os estudos da atividade da crotamina sobre a neurotransmissão, foram realizados por meio da avaliação da contração gerada por estimulação elétricas transmural e por meio de agente liberador de catecolaminas (tiramina).

O ducto deferente é um órgão cuja transmissão simpática se caracteriza pelo processo de co-transmissão (Figura 6), no qual os dois neurotransmissores principais envolvidos, noradrenalina e ATP, são liberados na fenda sináptica e atuam de modo sinérgico (Burnstock,1988). As contrações fásicas são caracterizadas por serem rápidas, uma vez que são provenientes da entrada de $\mathrm{Ca}^{2+}$ diretamente dos 
canais iônicos voltagem dependes. Quando esses estímulos são induzidos em baixas frequências, são representadas na forma de "twiches" (Figura 19).

A análise pré-sináptica em ensaios de estimulação elétrica em baixa frequência $(0,05 \mathrm{~Hz})$ demonstrou que a crotamina interfere no perfil de contratilidade da porção prostática do DDR, ou seja, possui influência na liberação de neurotransmissores ou age diretamente na musculatura. Como observado, a presença de crotamina provocou uma diminuição na contração fásica, resultado inesperado, uma vez que a crotamina é descrita como uma toxina despolarizante (Vital-Brazil et al, 1979). Esse efeito foi mais expressivo em concentrações de 0,1 $\mu \mathrm{g} / \mathrm{mL}$ e $0,5 \mu \mathrm{g} / \mathrm{mL}$, após 25 minutos, enquanto que, na concentração de $1 \mu \mathrm{g} / \mathrm{mL}$ de crotamina este efeito não foi tão significante (figura 20).

Sendo o ATP o principal neurotransmissor pela resposta de contração fásica observada neste ensaio (Figura 20), uma possível explicação seria que a crotamina promoveria uma diminuição da amplitude de contração e esse efeito poderia estar relacionado com uma interferência na liberação de ATP.

Segundo Koslov em 2013, a estimulação elétrica em frequências de 1, 5, 10 , $20 \mathrm{~Hz}$ de nervos simpáticos do DD de ratos, camundongos e coelhos resulta uma contração com dois componentes distintos, o componente fásico com características de contração rápida e curta e o componente mais lento, o tônico, devido ao processo de co-transmissão entre o ATP e a noradrenalina (Figura 21).

Em nosso estudo conseguimos observar que, a contração fásica na presença de crotamina $(1 \mu \mathrm{g} / \mathrm{ml})$ foi aumentada em relação ao controle na frequência de $20 \mathrm{~Hz}$ enquanto que, em concentração de $0,5 \mu \mathrm{g} / \mathrm{ml}$ parece existir uma tendência à diminuição da amplitude da contração (Figura 22).

Nos nossos estudos de contração induzida por estimulação elétrica $(0,05 \mathrm{~Hz})$ em relação ao tempo (Figura 20) evidenciamos uma diminuição da amplitude de contração, enquanto que nos estudos onde foi realizada a curva de frequência do componente fásico da contração (Figura 22), verificamos uma potencialização da contração fásica, havendo dessa forma um comportamento dual da crotamina, o que sugere um efeito bifásico provocado pela crotamina, que se modifica em função da dose e da frequência utilizadas, uma vez que, na concentração mais alta de $1 \mu \mathrm{g} / \mathrm{ml}$ houve o aumento da contração na frequência de $20 \mathrm{~Hz}$ (Figura 22) enquanto que em concentrações mais baixas $(0,1 \mu \mathrm{g} / \mathrm{ml}$ e $0,5 \mu \mathrm{g} / \mathrm{ml})$ este efeito foi contrário (Figura 20).

Dados da literatura mostram que, a porção prostática do DDR possui uma 
quantidade grande de um subtipo de canal de $\mathrm{Ca}^{2+}$ voltagem dependente que estaria associado a canais de $\mathrm{K}^{+}$(Boselli, 1998). Um suposto bloqueio ou uma abertura desses canais de $\mathrm{K}^{+}$do DDR poderia explicar o efeito verificados nos resultados de contração mediadas por estimulação elétrica transmural.

Segundo ensaios realizados por Peigneur, em 2012, a crotamina bloqueia de forma reversível algumas subunidades dos canais de $\mathrm{K}^{+}\left(\mathrm{K}_{\mathrm{v}}\right.$ 1.1., 1.2 e 1.3), sendo o mais sensível o $K_{v}$ 1.3. Contudo, de acordo com Ohya et al. em 1997, os canais de $\mathrm{K}^{+}$estão representados no DD pelas subunidades $\mathrm{K}_{\mathrm{v}} 1.4, \mathrm{~K}_{\mathrm{v}} 3.3, \mathrm{~K}_{\mathrm{v}} 3.4, \mathrm{~K}_{\mathrm{v}} 4.2$ e $\mathrm{K}_{\mathrm{v}} 4.3$ dificultando desta forma identificar o efeito da crotamina por este mecanismo. Porém, aceitando a hipótese da existência de um possível efeito bifásico, em concentrações maiores de crotamina, poderia haver uma perda de sua especificidade pelas subunidades dos canais de $\mathrm{K}^{+}$alvo passando a agir de forma inespecífica em canais de $\mathrm{K}^{+}$localizados no neurônio, se comportando assim como um agente despolarizante, aumentando a contração muscular corroborando os resultados evidenciados em ensaios realizados por Yount (2009) e HernandezOliveira e Silva (2013).

Por outro lado, este efeito bifásico pode ser justificado pela semelhança estrutural entre a crotamina e a $\beta$-defensinas, que são descritas por apresentar um comportamento bifásico em função da sua concentração, onde concentrações mais baixas promovem a ativação e a abertura de canais de $\mathrm{K}^{+}$dependentes de $\mathrm{Ca}^{2+}$, hiperpolarizando a célula e promovendo a diminuição da amplitude de contração, enquanto que em concentrações mais altas a $\beta$-defensinas promove o bloqueio desses canais de $\mathrm{K}^{+}$(Yount et al.,2009; Liu et al., 2013).

Analisando ainda os ensaios realizados em curva de frequências, observouse que a crotamina apresentou uma tendência à diminuição da contratilidade do componente tônico de contração na concentração de 0,1 e $0,5 \mu \mathrm{g} / \mathrm{mL}$ (Figura 23), sendo que a concentração de $0,1 \mu \mathrm{g} / \mathrm{mL}$ de crotamina causou uma diminuição estatisticamente diferente em relação ao controle em $10 \mathrm{~Hz}$. A contração tônica é mediada principalmente pelo neurotransmissor noradrenalina. A noradrenalina ativa receptores metabotrópicos $\alpha_{1}$-adrenérgicos das células musculares do vaso deferente, promovendo a liberação de $\mathrm{Ca}^{2+}$ dos estoques intracelulares e com isso promovendo a contração. A diminuição da amplitude de contração na concentração de $0,1 \mu \mathrm{g} / \mathrm{mL}$ de crotamina em $10 \mathrm{~Hz}$ pode também ser explicada pela semelhança estrutural entre a crotamina e a $\beta$-defensinas e sua ativação de canais de $\mathrm{K}^{+}$, uma vez que apresenta este efeito em concentrações de 0,1 e $0,5 \mu \mathrm{g} / \mathrm{mL}$. 
Além dos experimentos de estimulação elétrica, a tiramina também foi utilizada para estudar o componente pré-sináptico da neuroliberação de noradrenalina e verificar a interferência da crotamina e também do TEA na neuroliberação. O TEA foi utilizado como parâmetro de comparação para a crotamina que, segundo Yount et al. (2009) poderia agir bloqueando canais de $\mathrm{K}^{+}$ voltagem-dependente, já que o TEA já tem seu mecanismo conhecido como um bloqueador inespecífico de canais de $\mathrm{K}^{+}$.

A tiramina é um simpatomimético indireto que tem a capacidade de estimular a liberação de grandes quantidades de catecolaminas armazenadas nos terminais nervosos por meio da reversão do processo de receptação neuronal (Berg \& Jensen, 2013). Dessa forma, quando em contato com o DDR, a tiramina promove a liberação neuronal de noradrenalina, gerando uma contração tônica. Conforme observado na Figura 24, a crotamina (1 $\mu \mathrm{g} / \mathrm{mL})$ não interferiu significativamente na contração promovida pela tiramina em relação ao controle enquanto que, na presença de TEA (1000 mM) houve um aumento expressivo da contração. De acordo com esses resultados, concluímos que a crotamina na concentração de 1,0 $\mu \mathrm{g} / \mathrm{mL}$ não interfere na neuroliberação de noradrenalina induzida pela tiramina.

Esse resultado corrobora com o observado no experimento de contração induzido por EE onde o componente tônico foi avaliado (Figura 23) e não foi verificada alteração da contração com a concentração de $1,0 \mu \mathrm{g} / \mathrm{mL}$ de crotamina.

Nosso próximo passo foi analisar a interferência da crotamina no componente pós-sináptico de contração, nesse sentido, a porção prostática do DDR foi submetida a curvas dose-resposta de noradrenalina. A curva foi realizada após incubação por 30 minutos com crotamina em diferentes concentrações $(0,1 ; 0,5$ e $1 \mu \mathrm{g} / \mathrm{ml}$ ). Conforme observado na figura 25 e nos valores de $\mathrm{PD}_{2}$ e $\mathrm{E}_{\max }$ da Tabela 2, a crotamina não interferiu no perfil da curva dose-resposta de noradrenalina.

A curva dose-resposta também foi realizada na presença de TEA (100, 300 e $1000 \mu \mathrm{M})$. De acordo com a figura 26 e com a Tabela 3, os valores de $\mathrm{pD}_{2}$ não foram alterados e como esperado, o efeito máximo da noradrenalina foi aumentado na presença de TEA nas concentrações de $300 \mathrm{mM}$ e $1000 \mathrm{mM}$ confirmando seu mecanismo descrito por ser um bloqueador de canais de $\mathrm{K}^{+}$inespecífico.

Nos nossos estudos para avaliação o componente purinérgico pós-sináptico realizamos ensaios em que a porção prostática do DDR foi submetida à concentração única de $10^{-3} \mathrm{M}$ de ATP na ausência e na presença de crotamina $(1 \mu \mathrm{g} / \mathrm{mL})$ e de TEA $1000 \mu \mathrm{M}$ (Figura 27). Verificamos que a contração mediada pelo 33 
ATP exógeno não foi significativamente alterada pela crotamina, apesar desta promover uma tendência ao aumento da contração fásica, promovida pelo mesmo. O histograma representa a porcentagem de contração do DDR proporcionado por dose única de ATP $\left(10^{-3} \mathrm{M}\right)$ em relação ao efeito máximo proporcionado por concentração única de $\mathrm{KCl} 80 \mathrm{mM}$, o TEA, como esperado, aumentou significativamente a contração $(61 \pm 0,1 \%)$ pela sua ação em facilitar a despolarização da membrana celular.

Conforme observado nos experimentos em que o efeito da crotamina foi comparado com o efeito do TEA (dose única de tiramina e ATP e na curva concentração-resposta de noradrenalina) a crotamina não apresentou a característica despolarizante de um bloqueador de canais de $\mathrm{K}^{+}$como o TEA. Em todos os ensaios o TEA foi capaz de potencializar a amplitude de contração enquanto que a crotamina não apresentou esse padrão, sugerindo que esta não atue em canais de $\mathrm{K}^{+}$presentes no músculo liso do DDR. Contudo, nossos estudos indicam que a crotamina em concentração de $1 \mu \mathrm{g} / \mathrm{mL}$ possa potencializar a contração fásica em frequência de $20 \mathrm{~Hz}$ pela perda de especificidade de algum canal presente no neurônio, se comportando como um agente liberador de ATP.

Para compreender melhor a ação da crotamina serão necessários mais testes, uma vez que, em musculatura esquelética, seu efeito resulta em um aumento da contração (Hong \& Chang,1983), enquanto que, em musculatura lisa como demonstrado, ela apresenta uma tendência a diminuir a contração (Figura 20, Figura 23) e em certas ocasiões potencializa o componente fásico de contração em estudos de estimulação elétrica (Figura 22).

Dessa forma, os nossos resultados demonstram que a crotamina possui um efeito bifásico na neurotransmissão autonômica do DDR interferindo no componente pré-sináptico purinérgico e noradrenérgico mediados pelo ATP e pela noradrenalina não alterando o componente pós-sináptico de transmissão de ambos, nos nossos parâmetros de avaliação. 


\section{CONCLUSÕES}

- A toxina do veneno da Crotalus durissus terrificus, crotamina, foi efetivamente isolada por meio de técnicas cromatográficas;

- A pureza e massa da crotamina foram determinadas por espectrometria de massa, confirmando a efetividade do fracionamento e a identidade da toxina.

- Verificamos que a crotamina possui um efeito dual, dependendo da sua concentração, um efeito inibitório em concentrações de 0,1 e 0,5 $\mathrm{gg} / \mathrm{ml}$ e um efeito potencializador da contração na concentração de $1,0 \mu \mathrm{g} / \mathrm{ml} \mathrm{em}$ frequência de $20 \mathrm{~Hz}$.

- Os mecanismos que levam a essa potencialização ainda não estão bem esclarecidos, uma vez que os componentes pré-sinápticos de contração noradrenérgico e purinérgico foram alterados porém o componente póssináptico não foi alterado.

- A crotamina parece interferir na neuroliberação noradrenérgica e purinérgica, desencadeando a diminuição ou potencialização da contração (dose dependente) se comportando como a $\beta$-defensinas. 


\section{REFERÊNCIAS BIBLIOGRÁFICAS}

ALEXANDER, G.; GROTHUSEN, J.; ZEPEDA, H.; SCHWARTZMAN, R. Giroxin, a toxin from the venom of Crotalus durissus terrificus is thrombin like enzyme. In: Toxicon, $v$. 26 (10), p. 953-960, 1988.

ANTON, P.G.; DUNCAN, M.E.; MCGRATH, J.C. An analysis of the anatomical basis for the mechanicalresponse to motor nerve stimulation of the rat vas deferens. In: J Physiol. 273(1):23-43, 1977.

ARIENS EJ. Affinity and intrinsic activity in the theory of competitive inhibition. I. Problems and theory. In: Arch Int Pharmacodyn Ther. Sep 1;99(1):32-49, 1954.

BATRA, S.K. Sperm transport through vas deferens: review of hypotheses and suggestions for a quantitative model. In: Fertil Steril. 25(2):186-202, 1974.

BELTRAN, J.R.; MASCARENHAS, Y.P. SAXS study of the snake toxin $\alpha$-crotamine. In: Eur. Biophys., v. 17, p. 325-329, 1990.

BURNSTOCK, G. Sympathetic purinergic transmission in small blood vessels. In: Trends Pharmacol Sci. 9(4):116-7, 1988.

CAMILLO, M.A.; ARRUDA PAES, P.C. TRONCONE, L.R.; ROGERO, J.R. Gyroxin fails to modify in vitro release of labelled dopamine and acetylcholine from rat and mouse striatal tissue. In: Toxicon, v. 39(6), p. 843-853, 2001.

CAMPOS, L.A. Isolamento e caracterização da Delta-toxina do veneno de Crotalus durissus terrificus . Dissertação (Mestrado) - INSTITUTO DE PESQUISAS ENERGÉTICAS E NUCLEARES, 2006.

CARDOSO, J.L.C.; FRANCA, F.O.S.; WEN, F.H. Animais peçonhentos no Brasil: biologia, clínica e terapêutica dos acidentes. Acidente botrópico. In: França, F.O.S. \& Málaque, C.M.S. (Eds.). Editora Sarvier, São Paulo, p. 72-86, 2003.

CHANG, C C. Use of geographutoxin II (mu-conotoxin) for the study of neuromuscular transmission in mouse. In: British Journal of Pharmacology, v. 97, n. 3, p. 934-940, 1989.

CORONADO, M. A., GABDULKHAKOV, A., GEORGIEVA, D, SANKARAN, B. Structure of the polypeptide crotamine from the Brazilian rattlesnake Crotalus durissus terrificus. 
In: Biological Crystallography Acta Cryst. D69, 1958-1964, 2013.

DEVI, A. The chemistry, toxicity, biochemistry and pharmacology of North American Snake Venoms. In: Venomous Animals and Theier Venoms, v. II, Academic Press: New York p. $175-202,1971$.

DIAZ-TOLEDO, A.; JURKIEWICZ, A. Different mechanisms of action of agents acting on beta-adrenoceptors in barium-stimulated and electrically-stimulated rat vas deferens. In: Br J Pharmacol.; 104(1):277-83, 1991.

DONOSO V, SILVA M, ST-PIERRE S, HUIDOBRO-TORO JP. Neuropeptide Y (NPY), an endogenous presynaptic modulator of adrenergic neurotransmission in the rat vas deferens: structural and functional studies. In: Peptides. 1988.

ENDO, T.; OYA, M.; OZAWA, H. A proton nuclear magnetic resonance study on the solution structure of crotamine. In: J. Protein. Chem. v. 8 p. 807-815, 1989.

EVANGELISTA, S A M; MARTINS, M C; NASCIMENTO, R F; Renal and vascular effects of the natriuretic peptide isolated from Crotalus durissus cascavella venom. In: Toxicon, v. 52, n. 7, p. 737-744, 2008.

FAURE, G.; CHOUMET, V.; BOUCHIER, C.; CAMOIN, L.; GUILLAUME, J.L.; MONEGIER, B.; VUILHORGNE, M.; BON, C. The origin of the diversity of crotoxin isoforms in the venom of Crotalus durissus terrificus. In: Eur. J. Biochem., v. 223, p. 161-164, 1994.

FERREIRA JÚNIOR, R.S.; NASCIMENTO, N.; COUTO, R.; ALVES, J.B.; MEIRA, D.A.; BARRAVIEIRA, B. Laboratory Evaluation of Young Ovines Inoculated with Natural or 60Co-Irradiated Crotalus durissus terrificus Venom During Hyperimmunization Process. In: J. Venom. Anim. Toxins incl. Trop. Dis. v. 12(4), p. 620-631, 2006.

FLETCHER JE, HUBERT M, WIELAND SJ, GONG QH, JIANG MS. Similarities and differences in mechanisms of cardiotoxins, melittin and other myotoxins. In: Toxicon, 1996.

GARCEZ-DO-CARMO, L. Características da interação da serotonina com receptores serotoninérgicos e adrenérgicos em ducto deferente de rato. In: Tese de Doutorado em Ciências, Universidade Federal de São Paulo/antiga Escola Paulista de Medicina, 1995.

GONÇALVES, J.M. \& ARANTES, E.G. Estudos sobre venenos de serpentes brasileiras. 37 
III - Determinação quantitativa de crotamina no veneno de cascavel brasileira. In: An. Acad. Bras. Cienc., v. 28, p. 369-371, 1956.

GONÇALVES, J.M. \& VIEIRA, L.G. Estudos sobre venenos de serpentes brasileiras. I Análise eletroforética. In: Acad. Bras. Cienc., v. 22, p. 141-149, 1950.

GRAHAM, R.L., GRAHAM, C., MCCLEAN, S., CHEN, T., O'ROURKE, M., HIRST, D., THEAKSTON, D., SHAW, C. Identification and functional analysis of a novel bradykinin inhibitory peptide in the venoms of New World Crotalinae pit vipers. In: Biochem. Biophys. Res. Commun 338 (3), 1587-1592, 2005.

HAMPE, O.G.; VOZARI-HAMPE, M.M.; GONÇALVES, J.M. Crotamine conformation: effect of pH and temperature. In: Toxicon, v. 16, p. 453-460, 1978.

HERNANDEZ-OLIVEIRA, S.; TOYAMA, M.H.; TOYAMA, D.O.; MARANGONI, S.; HYSLOP, S.; RODRIGUES-SIMIONI, L. Biochemical, Pharmacological and Structural Characterization of a New PLA2 from Crotalus durissus terrificus (South American Rattlesnake). In: Venom. Protein J., v. 24(4), p. 233-242, 2005.

HERNANDEZ-OLIVEIRA E SILVA, S.; ROSTELATO-FERREIRA, S.; ROCHA-E-SILVA, T.A. Beneficial effect of crotamine in the treatment of myasthenic rats. In: Muscle Nerve. Apr;47(4):591-3, 2013.

HORTNAGEL, H. \& HANIN, J. Toxins affecting the cholinergic system. In. Selective neurotoxicity. Herken, H.; Hucho, F. (Eds.). Springer, Berlin Heldelberg New York, p. 293-332, 1992.

KASTURIRATNE, A.; WICKREMASINGHE, A.R.; DE SILVA, N., GUNAWARDENA, N.K.; PATHMESWARAN, A., PREMARATNA, R.; SAVIOLI, L.; LALLOO, D.G.; DE SILVA, H.J. Estimating the global burden of snakebite: A literature analysis. In: PLoS Med., v, 5(11), p. 1591-1604, 2008.

KERKIS, A; PEREIRA ; A., A. HAYASHI , M. A. Crotamine toxicity and efficacy in mouse models of melanoma. In: Expert Opinion on Investigational Drugs, vol. 20, no. 9, pp. 11891200, 2011.

KOSLOV, D. S.; ANDERSSON, K. E., Physiological and pharmacological aspects of the vas deferens-an update. In: Front Pharmacol. Aug 22;4:101, 2013. 
LAURE, C. J. Die Primär strutur des crotamins. In: Hope Seylers z. Physiol. Chem., v. 356 p. 213-215, 1975.

LIU, R.; ZHANG, Z.; LIU, H.; HOU, P.; Human $\beta$-defensin 2 Is a Novel Opener of $\mathrm{Ca}^{2+}$ Activated Potassium Channels and Induces Vasodilation and Hypotnsion in Monkeys. In: Hypertension, 62 p. 415 - 425, 2013.

MANCIN, A C; SOARES, A M; ANDRIÃO-ESCARSO, S H; The analgesic activity of crotamine, a neurotoxin from Crotalus durissus terrificus (South American rattlesnake) venom: a biochemical and pharmacological study. In: Toxicon, v. 36, n. 12, p. 19271937, 1998.

MÈNEZ, A; Les venins et toxines des serpents. In: Goyffon, M \& Heurtaut, J. (Eds) La function venimeuse, Masson, p. 200-220, 1994.

MINISTÉRIO DA SAÚDE. Estatística anual de casos de envenenamentos ofídicos. Disponível em: <http://portal.saude.gov.br/portal/saude/profissional>. Acesso em 05 mar. 2014.

MINNEMAN KP, ESBENSHADE TA. Alpha 1-adrenergic receptor subtypes. In: Annu Ver Pharmacol Toxicol; 34:117-33. Review, 1994.

MINNEMAN KP, HAN C, ABEL PW. Comparison of alpha 1-adrenergic receptor subtypes distinguished by chlorethylclonidine and WB 4101. In: Mol Pharmacol. 33(5):509$14,1988$.

MIRANDA HF, DURAN E, FERNANDEZ E, PINARDI G. Muscarinic receptor subtypes in the bisected vas deferens of the rat. In: Gen Pharmacol. 1995.

MITAKE, M. B.; COSTA, H.; SPENCER, P. J.; VASSILIEFF, V. S.; ROGERO, J. R. Effects of 60Co gamma radiation on crotamine. Brazil. In: J. Med. Biol. Reserch. v. 34 p. 15311538, 2001.

NICASTRO, G.; FRANZONI, L.; DE-CHIARA, C.; MANCIN, A. C.; GIGLIO, J. R.; SPISNI, A. Solution structure of crotamine, a $\mathrm{Na}^{+}$channel affecting toxin from Crotalus durissus terrificus venom. In: J. Med. Biol. Reserch v. 270, p. 1969-1979, 2003.

OHYA S.,TANAKA, M.; OKU, T.; ASAI Y.; WATANABE M.; GILES W.R.; IMAIZUMI, Y. 39 
Molecular cloning and tissue distribution of an alternatively spliced variant of an Atype $\mathrm{K}^{+}$channel alpha-subunit, Kv4.3 in the rat. In: FEBS Lett. Dec 22;420(1):47-53, 1997.

OLIVEIRA, K.C. Aspectos estruturais de proteínas do veneno crotálico modificadas por radiação ionizante. Dissertação (Mestrado) - Instituto de Pesquisas Energéticas e Nucleares, São Paulo, 2010.

PEIGNEUR, S; ORTS, J.B.; PRIETO DA SILVA, ALVARO R; Crotamine pharmacology revisited: novel insights based on the inhibition of KV channels. In: Molecular pharmacology, v. 82, n. 1, p. 90-96, 2012.

POUGH, F.H.; ANDREWS, R.M.; CADLE, J.E.; CRUMP M.L.; SAVITZKY, A.H.; WELLS K.D.; Herpetology In: Prentice-Hall, 1998.

PUPO, A.S. Functional effects of castration on alpha1-adrenoceptors in rat vas deferens. In: Eur J Pharmacol.19;351(2):217-23, 1998.

RÁDIS-BAPTISTA, G; KERKIS, I. Crotamine, a Small Basic Polypeptide Myotoxin from Rattlesnake Venom with Cell-Penetrating Properties. In: Current Pharmaceutical Design, 17, 4351-4361, 2011.

REPTILE DATABASE Espécies de serpentes distribuídas pelo mundo Disponível em <www.reptiledatabase.org> Acesso em 18 de outubro de 2014.

RIZZI, T; CARVALHO-DE-SOUZA, J; SCHIAVON, E; Crotamine inhibits preferentially fast-twitching muscles but is inactive on sodium channels. In: Toxicon, v. 50, n. 4, p. 553-562, 2007.

RODRIGUES, M.; SANTOS, A.; de la TORRE, B.G.; RÁDIS-BAPTISTA, G.; ANDREU, D.; SANTOS, N.C. Molecular characterization of the interaction of crotamine-derived nucleolar targeting peptides with lipid membranes. In: Biochimica and Biophysica Actano, v. 818(11), p. 2707-2717, 2012.

SLOTTA C.H. \& FRAENKEL-CONRAT, M. Purificação e cristalização do veneno da cobra cascavel. In: Mem. Inst. Butantan, v. 12, p. 505-513, 1938.

STARKE, K. Presynaptic alpha-autoreceptors. In: Rev Physiol Biochem Pharmacol.; 107:73-146, 1987. 
STOCKER, K.F. Composition of Snake Venoms. In: Medical Use of Snake Venom Proteins, CRC Press, Boca Raton, FL, p 33-56, 1990.

TERAMOTO, N. Physiological roles of ATP-sensitive K+ channels in smooth muscle. In: J Physiol. 1;572(Pt 3):617-24, 2006.

TERRADAS, D.; TABERNERO, A.; BADIA, A.; VIVAS, V.M. Different alpha1-adrenoceptorinduced inositol phosphate formation in the two portions of rat vas deferens. In: Naunyn Schmiedebergs Arch Pharmacol. 363(1):11-5, 2001.

TOYAMA, M. H.; CARNEIRO, E. M.; MARANGONI, S.; BARBOSA, R. L.; CORSO, G.; BOSCHERO, A. C. Biochemical characterization of two crotamine isoforms isolated by a single step RP-HPLC from Crotalus durissus terrificus (South American rattlesnake) venom and their action on insulin secretion by pancreatic islets. In: Biochem. et Biophis. Acta, v. 1474, p. 56-60, 2000.

TOYAMA, M. H.; MARANGONI, S. NOVELLO, J. C.; LEITE, G. B.; PRADO-FRANCESCHI, J.; CRUZ-HÖFLING, M. A.; RODRIGUES-SIMIONI, L. Biophisical, histopathological and pharmacological characterization of crotamine isoforms F22 and F32. In: Toxicon, v. 41, p. 493-500, 2006.

VAN ROSSUM JM. Cumulative dose-response curves. II. Technique for the making of dose-response curves in isolated organs and the evaluation of drug parameters. In: Arch Int Pharmacodyn Ther. 1963.

VARGAFTIG, B.B.; JOSEPH, D.; WAL, F.; MARLAS, G.; CHIGNARD, M.; CHEVANCE, G.L.; Convulxin induced activation of intact and of thrombin-degranulated rabbit platelets: specific crossed desensitization with collagen. In: Eur. J. Pharmacol., v. 92, p57 - 68, 1983.

VASSILEV P, MUTAFOVA-YAMBOLIEVA V, STANEVA-STOYTCHEVA D, TODOROV S. Involvement of calcium ions in the modulation of electrically-induced rat vas deferens contractions by histaminergic drugs. In: Gen Pharmacol. 1991.

VITAL BRAZIL, O. \& EXCELL, B.J. Action of crotoxin and crotactin from the venom of Crotalus durissus terrificus (South American rattlesnake) on the frog neuromuscular junction. In: J. Physiol., v. 212, p. 34-35, 1971. 
VITAL BRAZIL, O. Contribuição ao estudo do veneno ophídico. I - Espécies venenosas brasileiras; mortalidade por mordedura de cobras. In: Rev. Med. Trop. São Paulo, v. 4, p. 255-260, 1901.

VITAL BRAZIL, O. Venenos ofídicos neurotóxicos. In: Rev. Ass. Med. Bras., v. 26, p. 212218, 1980.

VITAL BRAZIL, O.; EUGÊNIO, A.G.B.; LASZLO, G.M. Origem da paralisia respiratória causada pela crotoxina. In: Ciênc. e Cult., v. 25, p. 1165-1169, 1973.

VITAL BRAZIL, O.; FRANCESCHI, J.P.; WAISBICH, E.P.Pharmacology of crystalline crotoxin. In: I. Toxicity. Mem. Inst. Butantan, v. 32, p. 973, 1966a.

VITAL BRAZIL, O.; FRANCESCHI, J.P.; WAISBICH, E.P.Pharmacology of crystalline crotoxin. In: II. Neuromuscular blocking action. Mem. Inst. Butantan, v. 33, p. 991-992, 1966b.

VITAL BRAZIL, O.; PRADO-FRANCHESI, J.P.; LAURE, C.J. Repetitive muscle responses induced by crotamine. In: Toxicon, v. 17, p. 61-67, 1979.

YAMANE, E.S.; BIZERRA, F.C.; OLIVEIRA, E.B.; MOREIRA, J.T.; RAJABI, M.; NUNES, G.L.; SOUZA, A.O.; SILVA, I.D.; YAMANE, T.; KARPEL, R.L.; SILVA, P.I. Jr.; HAYASHI, M.A. Unraveling the antifungal activity of a South American rattlesnake toxin crotamine. In: Biochimie. v. 95(2), p. 231-240, 2013.

YOUNT, N.Y.; KUPFERWASSER, D.; SPISNI, A.; DUTZ, S.M.; RAMJAN, Z.H.; SHARMA, S.; WARING A.J.; YEAMAN, M.R. Selective reciprocity in antimicrobial activity versus cytotoxicity of hBD-2 and crotamine. In: Proc Natl Acad Sci USA. v. 106, p. 14972-14977, 2009.

BERG, T.; JENSEN, J., Tyramine Reveals Failing $\boldsymbol{\alpha}_{2}$-Adrenoceptor Control of Catecholamine Release and Total Peripheral Vascular Resistance in Hypertensive Rats. In:Front Neurol. Feb 28;4:19. doi: 10.3389, 2013. 